\title{
A new atlas of temperature and salinity for the North Indian Ocean
}

\author{
A Chatterjee ${ }^{1, *}$, D Shankar ${ }^{1}$, S S C Shenoi ${ }^{2}$, G V Reddy ${ }^{1}$, G S Michael ${ }^{1}$, \\ M RaVichandran ${ }^{2}$, V V Gopalkrishna ${ }^{1}$, E P RAma RAO ${ }^{2}$, \\ T V S UDAYA BHASKAR ${ }^{2}$ and V N SANJEEVAN ${ }^{3}$ \\ ${ }^{1}$ National Institute of Oceanography (Council of Scientific and Industrial Research), \\ Dona Paula, Goa 403 004, India. \\ ${ }^{2}$ Indian National Centre for Ocean Information Services, Ocean Valley, Hyderabad 500 055, India. \\ ${ }^{3}$ Centre for Marine Living Resources and Ecology, Kendriya Bhavan, Kochi 682 037, India. \\ ${ }^{*}$ Corresponding author. e-mail: chatterjeea.ocean@gmail.com
}

The most used temperature and salinity climatology for the world ocean, including the Indian Ocean, is the World Ocean Atlas (WOA) (Antonov et al 2006, 2010; Locarnini et al 2006, 2010) because of the vast amount of data used in its preparation. The WOA climatology does not, however, include all the available hydrographic data from the Indian Exclusive Economic Zone (EEZ), leading to the potential for improvement if the data from this region are included to prepare a new climatology. We use all the data that went into the preparation of the WOA (Antonov et al 2010; Locarnini et al 2010), but add considerable data from Indian sources, to prepare new annual, seasonal, and monthly climatologies of temperature and salinity for the Indian Ocean. The addition of data improves the climatology considerably in the Indian EEZ, the differences between the new North Indian Ocean Atlas (NIOA) and WOA being most significant in the Bay of Bengal, where the patchiness seen in WOA, an artifact of the sparsity of data, was eliminated in NIOA. The significance of the new climatology is that it presents a more stable climatological value for the temperature and salinity fields in the Indian EEZ.

\section{Introduction}

The oceanographic atlas of the International Indian Ocean Expedition (IIOE) (Wyrtki 1971) marked a major step forward in our description of the hydrography of the Indian Ocean. For the first time, the temperature and salinity profiles collected over a few decades, including the IIOE data from the 1960s, were interpolated to provide a 'climatological' view of the variability. Monthly plots of sea surface temperature (SST) and bimonthly plots of sea surface salinity (SSS) were presented for the entire basin, and annual-mean plots of temperature and salinity were presented at 15 standard depths from 100-5000 m. Other atlases (see Stommel and Fieux 1978, for a list of atlases) had been more restricted in their coverage.

The next major development was the publication of a climatology of the world oceans (Levitus 1982). This atlas, which included data collected under several programmes and cruises, provided monthly climatological maps of temperature and salinity at standard depths up to $1000 \mathrm{~m}$ and seasonal or annual maps at deeper levels. It was also the first effort at presenting the seasonal cycle on the global scale (see Joseph Reid's foreword to Levitus 1982).

The atlas of Levitus (1982) has been updated to include new data; the methods used to create the

Keywords. Levitus atlas; temperature climatology; salinity climatology; Indian Exclusive Economic Zone. 
climatology have also been improved. An update of the atlas was issued in 1994 (Levitus and Boyer 1994; Levitus et al 1994); subsequent updates were issued in 2001 (Stephens et al 2002; Boyer et al 2002), 2005 (Antonov et al 2006; Locarnini et al 2006) (hereafter called WOA05), and 2009 (Antonov et al 2010; Locarnini et al 2010) (hereafter called WOA09). The plan is to release a new atlas once in four years to improve the climatology by including new data as they become available. (In the rest of this paper, we use the phrase 'Levitus atlas' or 'Levitus climatology' to refer to these atlases in general.) The data, sourced from several institutions across the world, are archived at the National Oceanographic Data Center (NODC) in the United States.

In the Indian Exclusive Economic Zone (EEZ), which covers a large part of the North Indian Ocean (NIO), and of the Bay of Bengal in particular, most of the data in the NODC database dates back to the 1960s (figure 1). Much of these data were collected during the IIOE (Wyrtki 1971). Subsequent restrictions on data sharing led to data from the Indian EEZ not being available to NODC, and the Levitus climatology therefore shows a sparse distribution of temperature and (particularly) salinity profiles in the Indian EEZ.

\section{Number of Profiles}

\section{Temperature}
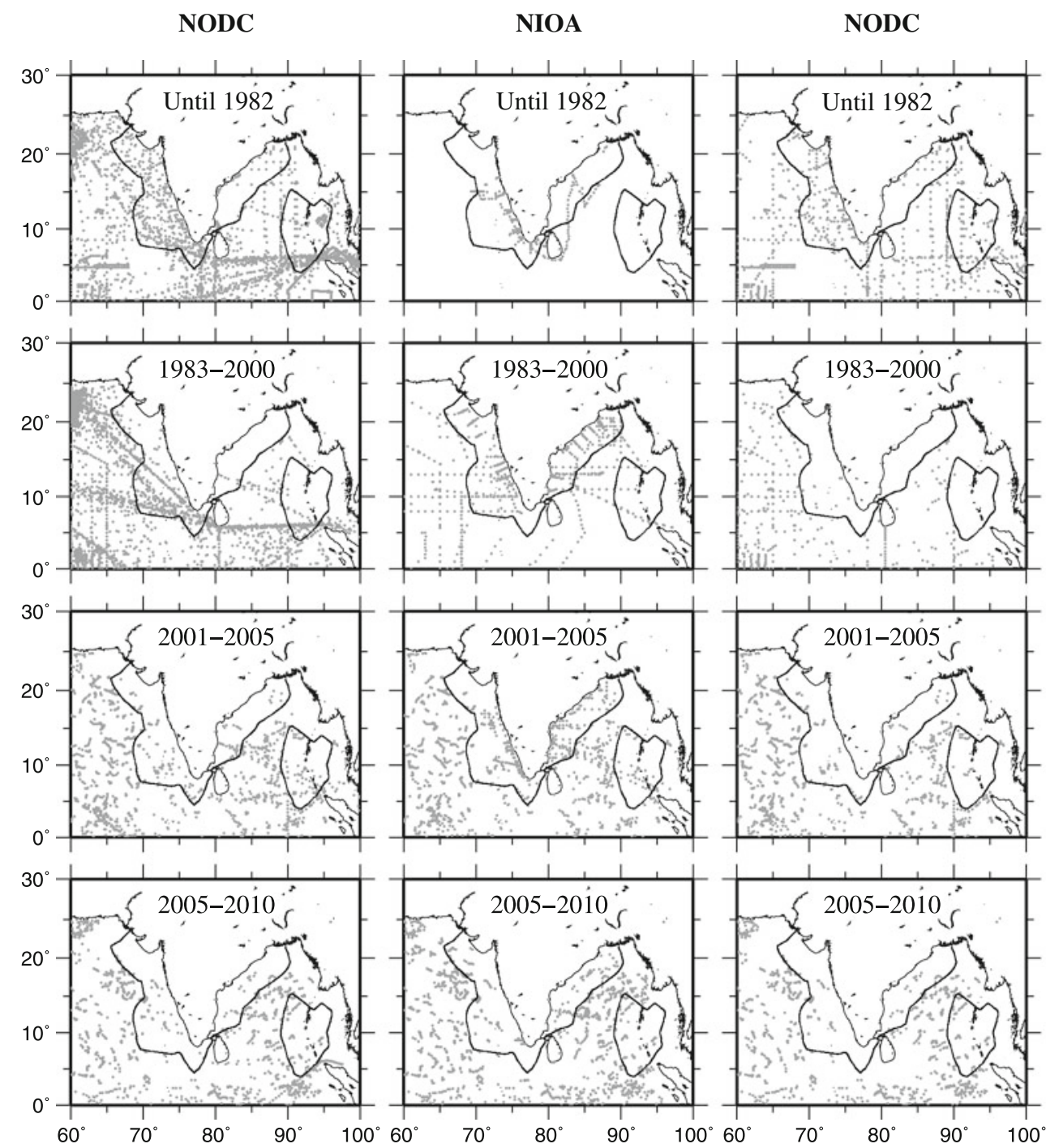

\section{Salinity}

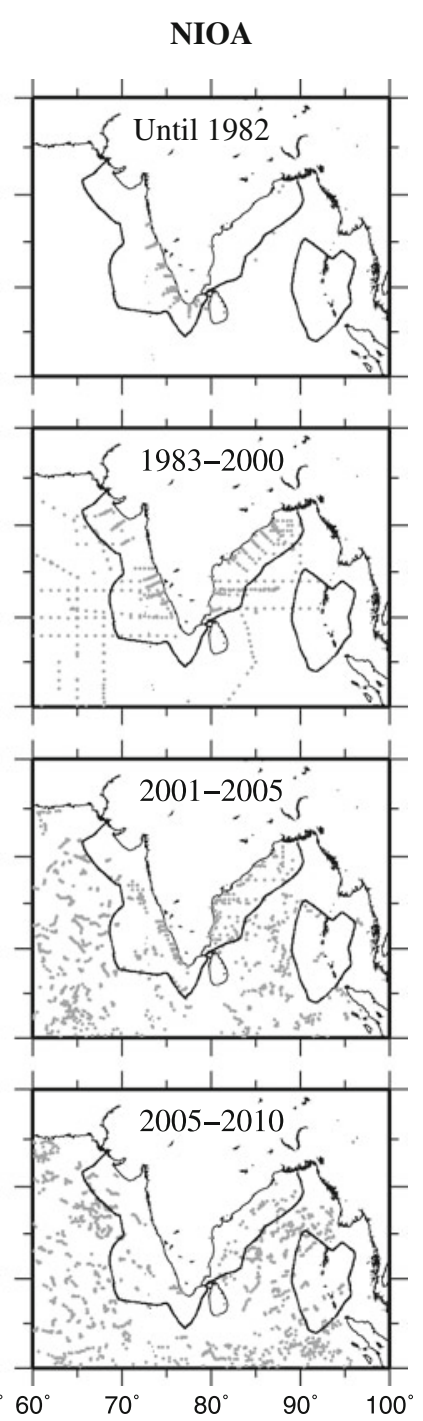

Figure 1. Spatial distribution of temperature and salinity profiles added to the NODC and Indian databases in various time intervals. Grey dot represents the position of a profile (before the quality and duplicate checks). The dark black line represents the Indian EEZ. After 1982, very few profiles were added in the Indian EEZ, particularly in the Bay of Bengal, to the NODC database. 
Hence, over a large part of the Indian EEZ, and in the Bay of Bengal in particular, the Levitus climatology is prepared by extrapolating from regions where data exist, leading to doubts over the validity of the climatology in these data-void regions. When model simulations tend to disagree with the climatology, it is often difficult to decide if this disagreement is a consequence of errors in the model simulation or in the climatology.

Over the years, the methods used to create the climatology have undergone changes (Boyer et al 2002; Antonov et al 2010; Locarnini et al 2010), resulting in differences between the climatologies even for the same data source. The largest changes tend to occur in the data-sparse Bay of Bengal (figure 2). This change in the bay is due more to changes in method than to an increase in the number of profiles in the NODC database. In summary, the climatology of a data-sparse region is more susceptible to changes in the methods used to create the climatology. Hence, data from Indian sources can help improve the climatology of temperature and salinity in the NIO, with the most significant improvements to be expected in the Indian EEZ.

This inclusion of data from Indian sources into the Levitus climatology is the objective of this paper. The domain over which we carried out the
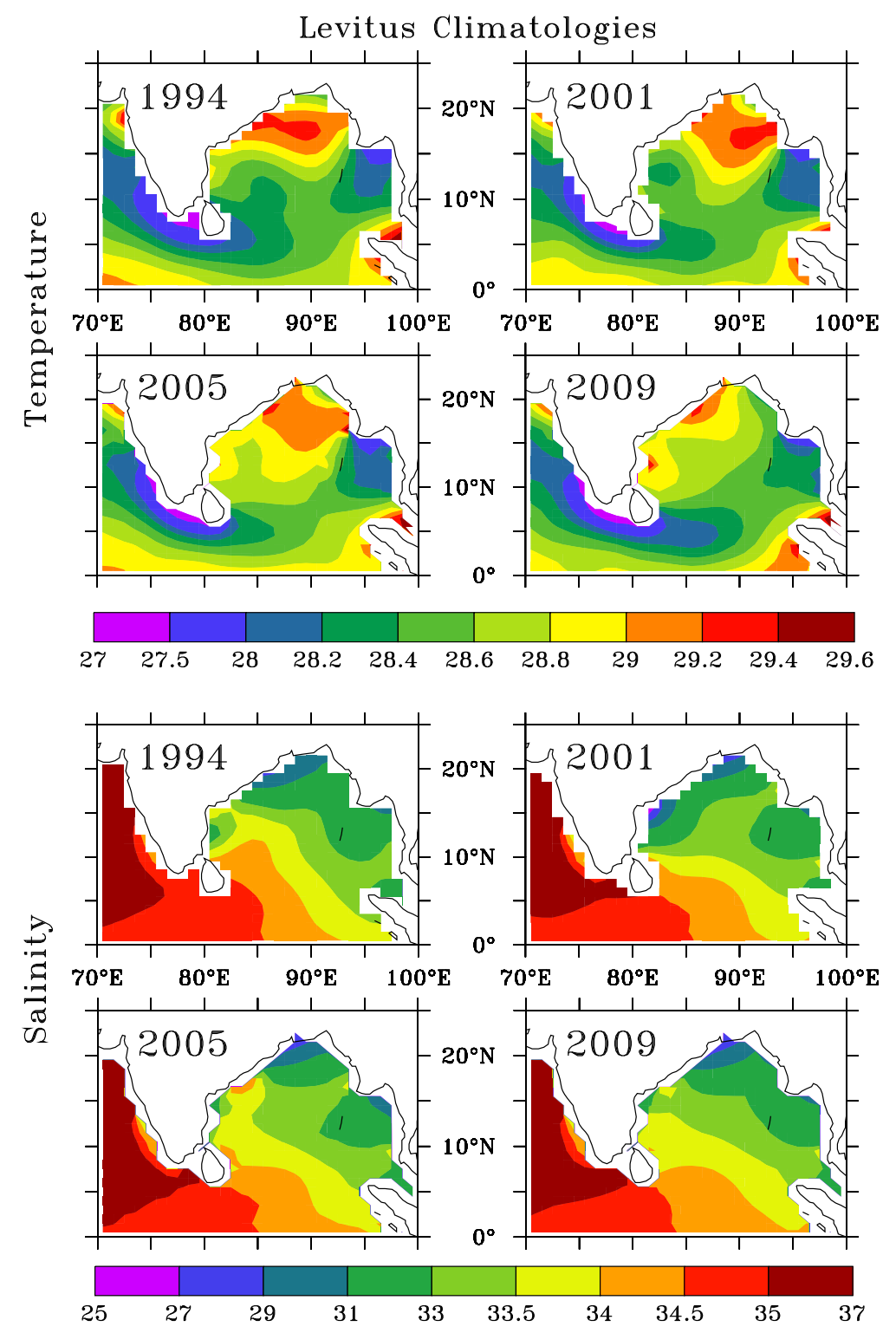

Figure 2. Comparison of surface temperature $\left({ }^{\circ} \mathrm{C}\right)$ and salinity (PSU or practical salinity unit) for July from the Levitus atlases. This figure shows that the change in temperature and salinity contour in the Bay of Bengal, particularly in the Indian EEZ, is more due to changes in method than to an increase in the number of profiles (in all figures, temperature is in ${ }^{\circ} \mathrm{C}$ and salinity in PSU). 
Table 1. Sources of the datasets used in this climatology.

\begin{tabular}{ll}
\hline Data source & URL \\
\hline World Ocean Database & http://www.nodc.noaa.gov/OC5/WOD09/pr_wod09.html \\
Indian National Oceanographic Data Center & http://www.nio.org/index/option/com_url/task/frame/title/ \\
& Cruise\%20Reports\%20and\%20Data/tid/2/sid/18/thid/53 \\
Japan Oceanography Data Center & http://jdoss1.jodc.go.jp/cgi-bin/2001/feti_scalar \\
ARGO floats Data & http://www.incois.gov.in/Incois/incois1024/index/index.jsp?res=1024 \\
World Ocean Atlas 2009 & http://www.nodc.noaa.gov/OC5/WOA09/woa09data.html \\
World Ocean Atlas 2005 & http://www.nodc.noaa.gov/OC5/WOA05/pr_woa05.html \\
World Ocean Atlas 2001 & http://www.nodc.noaa.gov/OC5/WOA01/pr_woa01.html
\end{tabular}

Table 2. The sources of the temperature and salinity profiles used to prepare the new climatology are listed here. The main source was the National Oceanographic Data Center (NODC); other sources were the Japanese Oceanographic Data Center (JODC), Central Marine Fisheries Research Institute (CMFRI) in India, Indian National Centre for Ocean Information Services (INCOIS), the Indian National Oceanographic Data Centre (INODC), and the Center for Marine Living Resources and Ecology (CMLRE). The numbers in parentheses refer to the data from the Indian EEZ (including the part around the Andaman and Nicobar Islands).

\begin{tabular}{|c|c|c|c|c|c|}
\hline & \multirow[b]{2}{*}{ Instrument } & \multicolumn{2}{|c|}{ Before quality check } & \multicolumn{2}{|c|}{ After all quality checks } \\
\hline & & Temperature & Salinity & Temperature & Salinity \\
\hline \multirow[t]{9}{*}{ NODC } & $\operatorname{Total}(\mathrm{M}+\mathrm{A})$ & $417277(17039+7434)$ & $139456(6200+2141)$ & $356759(15197+6581)$ & $108232(4943+1501)$ \\
\hline & $\mathrm{CTD}(\mathrm{M}+\mathrm{A})$ & $11735(212+72)$ & $11407(183+64)$ & $8992(159+69)$ & $8478(127+59)$ \\
\hline & $\mathrm{XBT}(\mathrm{M}+\mathrm{A})$ & $164915(6711+3660)$ & - & $138624(6376+3463)$ & - \\
\hline & $\operatorname{MBT}(\mathrm{M}+\mathrm{A})$ & $100825(3864+1539)$ & - & $89058(3474+1041)$ & - \\
\hline & $\mathrm{OSD}(\mathrm{M}+\mathrm{A})$ & $57023(3901+731)$ & $51900(3666+645)$ & $45195(2900+580)$ & $39739(2722+476)$ \\
\hline & $\operatorname{PFL}(\mathrm{M}+\mathrm{A})$ & $62976(2351+1021)$ & $62929(32351+1021)$ & $61561(2288+1017)$ & $55332(2094+966)$ \\
\hline & $\operatorname{MRB}(\mathrm{M}+\mathrm{A})$ & $11856(0+411)$ & $9392(0+411)$ & $11579(0+411)$ & $4640(0+0)$ \\
\hline & $\mathrm{DRB}(\mathrm{M}+\mathrm{A})$ & $4119(0+0)$ & - & $1670(0+0)$ & - \\
\hline & $\mathrm{UOR}(\mathrm{M}+\mathrm{A})$ & $3827(0+0)$ & $3827(0+0)$ & $80(0+0)$ & $43(0+0)$ \\
\hline \multirow[t]{6}{*}{ INODC } & $\operatorname{Total}(\mathrm{M}+\mathrm{A})$ & $16573(7997+871)$ & $10870(5604+366)$ & $13239(6390+761)$ & $7891(4081+247)$ \\
\hline & CTD & $7256(2861+266)$ & $9508(4707+447)$ & $4918(1730+180)$ & $4633(1619+155)$ \\
\hline & $\mathrm{XBT}$ & $3770(1307+442)$ & - & $3527(1242+423)$ & - \\
\hline & $\mathrm{MBT}$ & $1607(853+63)$ & - & $1281(832+62)$ & - \\
\hline & Hydro cast & $3678(2770+100)$ & $3651(2743+100)$ & $3374(2530+96)$ & $3258(2462+92)$ \\
\hline & DBT & $262(206+0)$ & - & $139(85+0)$ & - \\
\hline INCOIS & ARGO & $75843(3159+1228)$ & $74647(3033+1233)$ & $39070(1520+557)$ & $37730(1453+561)$ \\
\hline \multirow[t]{6}{*}{ JODC } & $\operatorname{Total}(\mathrm{M}+\mathrm{A})$ & $4383(274+72)$ & $606(6+4)$ & $2965(103+58)$ & $342(0+2)$ \\
\hline & CTD & $1(0+0)$ & $1(0+0)$ & $1(0+0)$ & $1(0+0)$ \\
\hline & $\mathrm{XBT}$ & $184(0+0)$ & - & $126(0+0)$ & - \\
\hline & $\mathrm{MBT}$ & $132(0+0)$ & - & $87(0+0)$ & - \\
\hline & OSD & $254(0+0)$ & $249(0+0)$ & $173(0+0)$ & $168(0+0)$ \\
\hline & Unknown & $3812(274+72)$ & $356(6+4)$ & $2578(103+58)$ & $173(0+2)$ \\
\hline CMFRI & OSD & $1432(1416+0)$ & $1390(1374+0)$ & $1200(1185+0)$ & $1171(1156+0)$ \\
\hline CMLRE & $\mathrm{CTD}$ & $2264(1848+181)$ & $2262(1846+181)$ & $1927(1590+170)$ & $1898(1564+172)$ \\
\hline Total & - & $51772(31733+9786)$ & $229258(18063+3925)$ & $41516(25985+8127)$ & $157264(13197+2483)$ \\
\hline
\end{tabular}

analysis extended from $30^{\circ}$ to $120^{\circ} \mathrm{E}$ and $30^{\circ} \mathrm{S}$ to $30^{\circ} \mathrm{N}$. We present the data sources in section 2 , discuss the method of interpolation in section 3, and present the results, i.e., the new climatology, in section 4 . In section 5 , we discuss the method and conclude the paper.

\section{Data and quality control}

We obtained data from several sources (tables 1,2) for preparing this climatology. The main source was NODC; additional data were obtained from the Japanese Oceanographic Data Center (JODC), 
the Indian National Oceanographic Data Centre (INODC) at the National Institute of Oceanography, the Central Marine Fisheries Research Institute (CMFRI) at Kochi, the Indian National Centre for Ocean Information Services (INCOIS) at Hyderabad, and Centre for Marine Living Resources and Ecology (CMLRE) at Kochi. When one uses data from different sources, some profiles are duplicated across the datasets. Data from other sources were matched against the data from NODC, and duplicate profiles in these datasets were eliminated.

The NODC data include profiles from a variety of instruments: Conductivity-Temperature-Depth (CTD), Expendable Bathythermograph (XBT), Mechanical Bathythermograph (MBT), hydrocasts (or Ocean Station data, OSD), Profiling Floats (PFL), Moored Buoys (MRB), Drifting Buoys (DRB), and Undulating Oceanographic Recorders (UOR). The JODC data were mostly duplicated in the NODC database, which was considered the primary database, resulting in most of the JODC data being discarded. The remaining data were primarily from XBTs, MBTs, and hydrocasts; the source of several JODC profiles could not be determined. The CMFRI data were entirely hydrocasts and the INCOIS data were from Argo floats. The INODC database, the second largest for the Indian Ocean after that of the NODC, included data from CTDs, XBTs, MBTs, hydrocasts, digital bathythermograph data (DBT) and Argo floats.

A total of 517,772 temperature profiles and 229,258 salinity profiles were obtained from the above sources. After all quality control checks, 415,160 temperature and 157,264 salinity profiles were used for the annual climatology, which implied an addition of 58,401 temperature and 49,032 salinity profiles to the WOA09 database. In the Indian EEZ, the INODC database contributed 3670 CTD profiles, an increase of over an order of magnitude in comparison to the 288 profiles in the NODC database. Including other instruments, over 50\% (20\%) profiles were added in the Indian EEZ around the Indian mainland (Andaman and Nicobar Islands). Figure 3 shows the number of new profiles added in this climatology and the total number of profiles in the new database. If we exclude the Argo profiles, most of the new profiles are from the eastern Arabian Sea and the Bay of Bengal. Even after the addition of new data, however, some data-sparse regions remain: eastern Bay of Bengal, the Andaman Sea, and the Indian Ocean south of $15^{\circ} \mathrm{S}$ are the regions with the poorest coverage.

Before the profile data are mapped to a regular spatial and temporal grid, it is necessary to interpolate them to standard depth levels. A necessary pre-requisite for interpolation is ensuring the quality of the data. As described above,
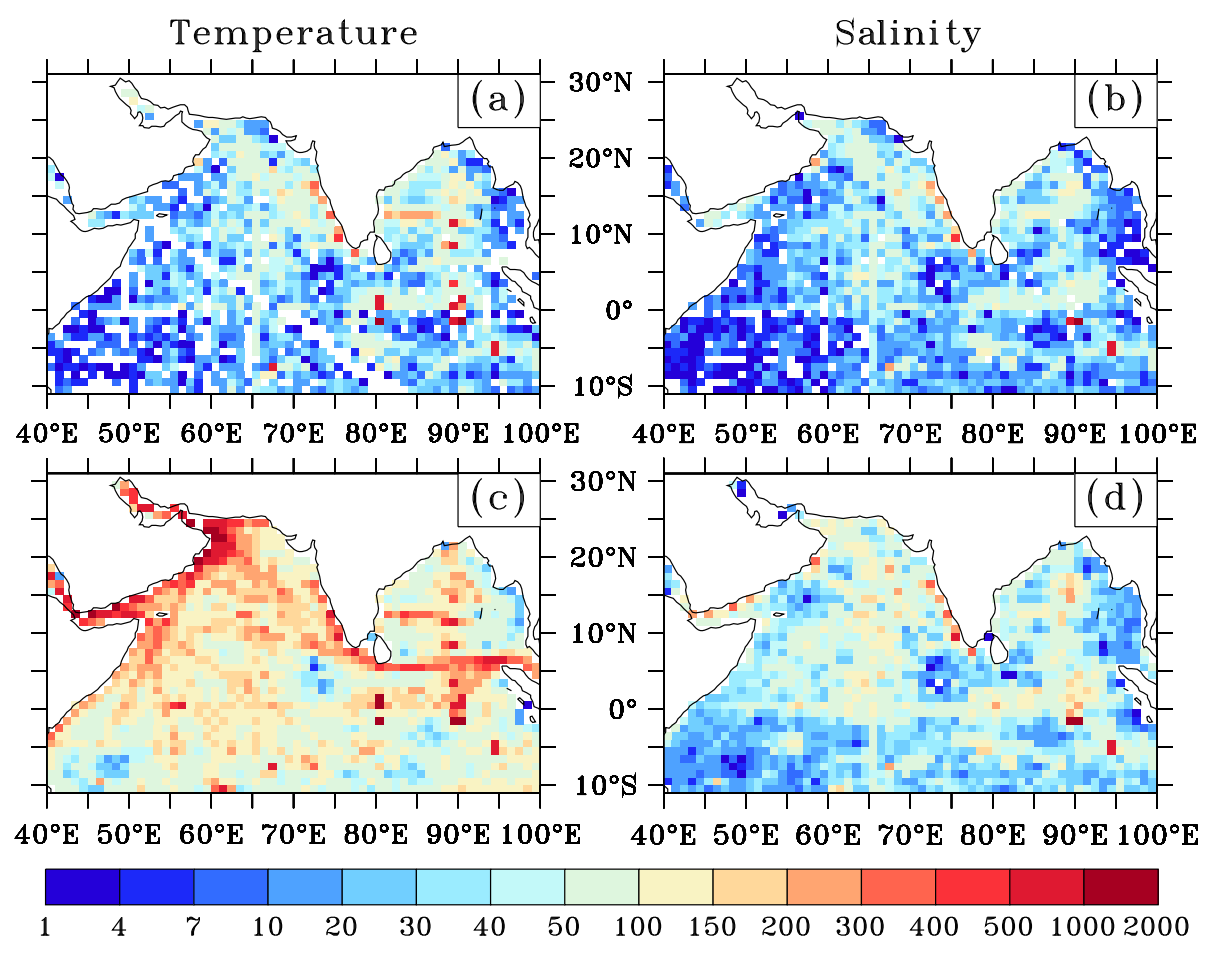

Figure 3. (a) Number of temperature profiles added in this climatology over that in the 2009 Levitus (WOA09) atlas for the annual climatology; (b) same as (a), but for salinity; (c) total number of temperature profiles used for annual climatology. (d) Same as (c), but for salinity. 
the first step in quality control of the data was the detection and elimination of duplicate profiles. The quality control for each profile was done following the procedure established in preparing the Levitus atlases (Boyer and Levitus 1994; Levitus and Boyer 1994; Levitus et al 1994; Boyer et al 2002; Stephens et al 2002; Antonov et al 2006, 2010; Locarnini et al 2006, 2010). These qualitycontrol steps are described in greater detail in Appendix A. Scientific quality-control procedures developed during TOGA (Tropical-Ocean Global Atmosphere) and WOCE (World Ocean Circulation Experiment) (Bailey et al 1994; Daneshzadeh et al 1994) were not used (except for XBT data) in the preparation of this atlas. Our aim is to improve the WOA climatology (in the Indian EEZ, in particular) and we intend merging this climatology with WOA so that a single database, representative of the Indian seas, is available. Therefore, we have used a quality-control procedure similar to that used for WOA.

\section{Methods}

The quality-controlled temperature and salinity profiles had to be interpolated to standard depth levels in the vertical and to a uniform $1^{\circ} \times 1^{\circ}$ grid in the horizontal. The interpolation methods are described in this section.

\subsection{Vertical interpolation}

All profile data were interpolated to the standard depth levels used in the Levitus atlases. In the Indian Ocean, there are 33 levels for the seasonal and annual climatologies: $0-30 \mathrm{~m}$ in steps of $10 \mathrm{~m}$ (4 levels), $30-50 \mathrm{~m}$ in a $20-\mathrm{m}$ step (1 level), 50$150 \mathrm{~m}$ in steps of $25 \mathrm{~m}$ (4 levels), $150-300 \mathrm{~m}$ in steps of $50 \mathrm{~m}$ (3 levels), $300-1500 \mathrm{~m}$ in steps of $100 \mathrm{~m}$ (12 levels), $1500-2000 \mathrm{~m}$ in steps of $250 \mathrm{~m}$ (2 levels), and 2000-5500 $\mathrm{m}$ in steps of $500 \mathrm{~m}$ (7 levels). The monthly climatology is restricted to $1500 \mathrm{~m}$ (24 levels).

If the first observation of a profile was within the top $5 \mathrm{~m}$, then we considered it a measurement at the surface $(0 \mathrm{~m})$. If an observation occurred exactly at a standard-depth level, then a direct substitution was made. Else, an interpolation procedure was used. The procedure followed WOA09 and is based on Rattray (1962) and Reiniger and Ross (1968). Four observed-depth-level values surrounding a standard-depth level were used, with two values each from above and below the standard level. The pair of values farthest from (closest to) the standard level are termed exterior (interior) points. Two three-point Lagrangian interpolations were carried out with two pairs of three values: one pair had one value above and two below the standard-depth level, and the other pair had two values above and one below the standard-depth level. The two values were averaged and fit to a reference curve (Reiniger and Ross 1968; Boyer and Levitus 1994). As noted by Levitus and Boyer (1994), using two three-point interpolations 'creates fewer spurious extrema in regions of large vertical gradient than does a single three-point interpolation'. Spurious extrema are values outside the range bounded by the nearest observed values, and when the method of Reiniger and Ross (1968) led to such spurious extrema, linear interpolation was used instead.

In the above method, it is important to define tolerance levels for the maximum separation between the observation level and the standarddepth level. These criteria followed Levitus and Boyer (1994). The first (second) criterion limited the maximum distance between the standard level and the interior (exterior) points. The interior points have a greater influence on the interpolated value, implying a stricter constraint due to the first criterion. Hence, if the first depth criterion, called inner distance, was violated, no standardlevel value was computed. If only the second depth criterion, called outer distance, was violated, linear interpolation was used instead. The depth criteria for inner and outer distances are listed in table 3 .

If four such points were not available for interpolation, but three points (two above and one below the standard-depth level, or one above and two below) were available, then we used threepoint Lagrangian interpolation. If only one point was available above and below the standard-depth level, then linear interpolation was used. Linear interpolation was also used if an overshoot occurred while using three-point interpolation. (We define overshooting as any interpolated value outside the range defined by the maximum and minimum values of the used observed-level measurements.)

For some XBT profiles in the western Arabian Sea, there was a large difference between the depths of two consecutive measurements: often, the first measurement was near the surface and the next was below $100 \mathrm{~m}$. In such a situation, which occurs when the surface temperature measurement is based on bucket samples, three-point interpolation results in an overshoot. Hence, we had to interpolate differently for these profiles. We evaluated the ratio of temperature difference and depth difference (linear temperature gradient between the two observations). If this ratio was less than $0.004^{\circ} \mathrm{C} \mathrm{m}^{-1}$, and the depth of both observations was less than $200 \mathrm{~m}$, then we used linear interpolation. If both these conditions were not satisfied, we avoided interpolating the data and the 
Table 3. Inner and outer distances used in the four-point vertical interpolation (Reiniger and Ross 1968). The values are as in Levitus and Boyer (1994). The standard depth and inner and outer distances are in metres.

\begin{tabular}{|c|c|c|c|}
\hline $\begin{array}{l}\text { Standard } \\
\text { level }\end{array}$ & $\begin{array}{l}\text { Standard } \\
\text { depth }\end{array}$ & $\begin{array}{c}\text { Inner } \\
\text { distance }\end{array}$ & $\begin{array}{c}\text { Outer } \\
\text { distance }\end{array}$ \\
\hline 1 & 0 & 5 & - \\
\hline 2 & 10 & 50 & 200 \\
\hline 3 & 20 & 50 & 200 \\
\hline 4 & 30 & 50 & 200 \\
\hline 5 & 50 & 50 & 200 \\
\hline 6 & 75 & 50 & 200 \\
\hline 7 & 100 & 50 & 200 \\
\hline 8 & 125 & 50 & 200 \\
\hline 9 & 150 & 50 & 200 \\
\hline 10 & 200 & 50 & 200 \\
\hline 11 & 250 & 100 & 200 \\
\hline 12 & 300 & 100 & 200 \\
\hline 13 & 400 & 100 & 200 \\
\hline 14 & 500 & 100 & 400 \\
\hline 15 & 600 & 100 & 400 \\
\hline 16 & 700 & 100 & 400 \\
\hline 17 & 800 & 100 & 400 \\
\hline 18 & 900 & 200 & 400 \\
\hline 19 & 1000 & 200 & 400 \\
\hline 20 & 1100 & 200 & 400 \\
\hline 21 & 1200 & 200 & 400 \\
\hline 22 & 1300 & 200 & 1000 \\
\hline 23 & 1400 & 200 & 1000 \\
\hline 24 & 1500 & 200 & 1000 \\
\hline 25 & 1750 & 200 & 1000 \\
\hline 26 & 2000 & 1000 & 1000 \\
\hline 27 & 2500 & 1000 & 1000 \\
\hline 28 & 3000 & 1000 & 1000 \\
\hline 29 & 3500 & 1000 & 1000 \\
\hline 30 & 4000 & 1000 & 1000 \\
\hline 31 & 4500 & 1000 & 1000 \\
\hline 32 & 5000 & 1000 & 1000 \\
\hline 33 & 5500 & 1000 & 1000 \\
\hline
\end{tabular}

interpolated profile was left without data at some standard levels.

\subsection{Horizontal interpolation: Objective analysis}

The next step, following vertical interpolation of the observations to standard depths, is interpolating the profiles onto a standard $1^{\circ} \times 1^{\circ}$ grid. We tried several methods to map the profile data onto a $1^{\circ} \times 1^{\circ}$ grid, but the method finally used was that in WOA05. The WOA05 method is described in this section; the other methods and the reasons for their failure are discussed in section 5.2.

WOA05 uses a simple, but iterative, averaging procedure to derive the monthly climatology. The inputs at each major step in the procedure are the observed mean field $X_{\mathrm{om}}$, a first-guess field $X_{\mathrm{fg}}$, and an influence radius $R$ for each $1^{\circ} \times 1^{\circ}$ grid cell. The iterative procedure refines the first-guess value used for each cell. For a given cell, its firstguess value $X_{\mathrm{fg}}$ is corrected by a correction factor that is determined using the $X_{\mathrm{om}}$ values of all cells within an 'influence radius' $R$ of the cell. The weight assigned to the $X_{\mathrm{om}}$ for a neighbourhood cell decreases as the square of its distance from the given cell, i.e., the method uses an inverse-distancesquared weighting to limit the distance to which an observation influences the climatology.

\subsubsection{Analysed annual climatology}

The first step in the iterative procedure is to estimate an analysed annual climatology. At this stage, $X_{\text {om }}$ for each cell is the annual mean value for that cell, i.e., the average of all data values available in the cell, irrespective of month or year, and $X_{\mathrm{fg}}$ is the annual zonal-mean value, i.e., the basin-wise average of the values for every $1^{\circ} \times 1^{\circ}$ latitude belt. (Note that the definition of 'basin' ensures that data from the Bay of Bengal do not influence the Arabian Sea and vice versa.) Using the zonal mean ensures that each cell has a first-guess value. The following procedure is then used to estimate the analysed annual climatology.

- Determine $X_{\mathrm{fg}}$ for each cell: use the annual, zonal-mean value.

- Use Barnes's interpolation method (Barnes 1964) to correct $X_{\mathrm{fg}}$ for each cell using the $X_{\mathrm{om}}$ of all cells within a distance $R$ of the cell. In this method, a correction factor $C^{i, j}$ is computed for each cell as follows.

$$
C^{i, j}=\frac{\sum_{s=1}^{n} W_{s} Q_{s}}{\sum_{s=1}^{n} W_{s}},
$$

where $i$ and $j$ represent the coordinate of a cell in the zonal and meridional directions, respectively, $C^{i, j}$ is the correction factor for cell $(i, j), n$ is the number of grid cells with non-zero $X_{\text {om }}$ within a distance $R$ of cell $(i, j), Q_{s}$ is the difference between $X_{\mathrm{om}}$ and $X_{\mathrm{fg}}$ in the sth cell within a distance $R$ of cell $(i, j)$, and $W_{s}$ is the weight assigned to the value $Q_{s}$ in cell $s$. The weight $W_{s}$ is given by:

$$
W_{s}=\left\{\begin{array}{ll}
\exp \left[\frac{-E r^{2}}{R^{2}}\right] & \text { if } r \leq R \\
0 & \text { if } r>R
\end{array},\right.
$$

where $E=4$ and $r$ is the distance of the cell $s$ from cell $(i, j)$. A detailed discussion of the Barnes (1964) weight function is given in Boyer et al (2002). 
- For each cell $(i, j)$, compute an analysed value.

$$
Y_{\mathrm{a}}^{i, j}=X_{\mathrm{fg}}^{i, j}+C^{i, j} .
$$

If there is no non-zero $X_{\mathrm{om}}$ within the influence radius $R$, the $C^{i, j}$ for the cell is set to zero and the first-guess value $X_{\mathrm{fg}}$ is left unchanged, i.e., $Y_{\mathrm{a}}^{i, j}=X_{\mathrm{fg}}^{i, j}$.

- Apply this correction procedure to all cells in the domain to produce the analysed annual climatology. The correction procedure is applied thrice successively, with $R$ being decreased each time: the values of $R$ used were 888, 666 and $444 \mathrm{~km}$ (approximately $8^{\circ}, 6^{\circ}$ and $4^{\circ}$ ).

\subsubsection{Analysed seasonal climatology}

The second step in the iterative procedure is to estimate an analysed seasonal climatology. As in Levitus climatologies, the four seasons we considered are as follows.

1. Winter: January-February-March

2. Spring: April-May-June

3. Summer: July-August-September

4. Fall: October-November-December

However, since the seasonal variability in the NIO, our region of interest, is dominated by the monsoonal cycle, we also redefined the Levitus seasons to create another set of seasonal and the corresponding monthly and annual climatologies to suit the variability in this region. The impact of this redefinition of seasons is discussed in section 5.1.

At this stage, $X_{\mathrm{om}}$ for each cell is the seasonal mean value for that cell, i.e., the average of all data values available in the cell for a given season, irrespective of month (within the season) or year, and $X_{\mathrm{fg}}$ is the annual analysed climatology estimated in the previous step.

As done for the annual analysed climatology, the next step in the procedure is Barnes's interpolation (items $2-4$ in section 3.2.1). The resulting field constitutes the analysed seasonal climatology.

\subsubsection{Analysed monthly climatology}

The third step is to estimate the analysed monthly climatology. Unlike in the first two steps, the computations in this step are restricted to $1500 \mathrm{~m}$ and above; relative scarcity of data and the relative lack of seasonal change below $1500 \mathrm{~m}$ imply that only the seasonal and annual climatologies can be estimated for the deeper ocean (Levitus 1982).

At this stage, $X_{\mathrm{om}}$ for each cell is the monthly mean value for that cell, i.e., the average of all data values available in the cell for a given month,
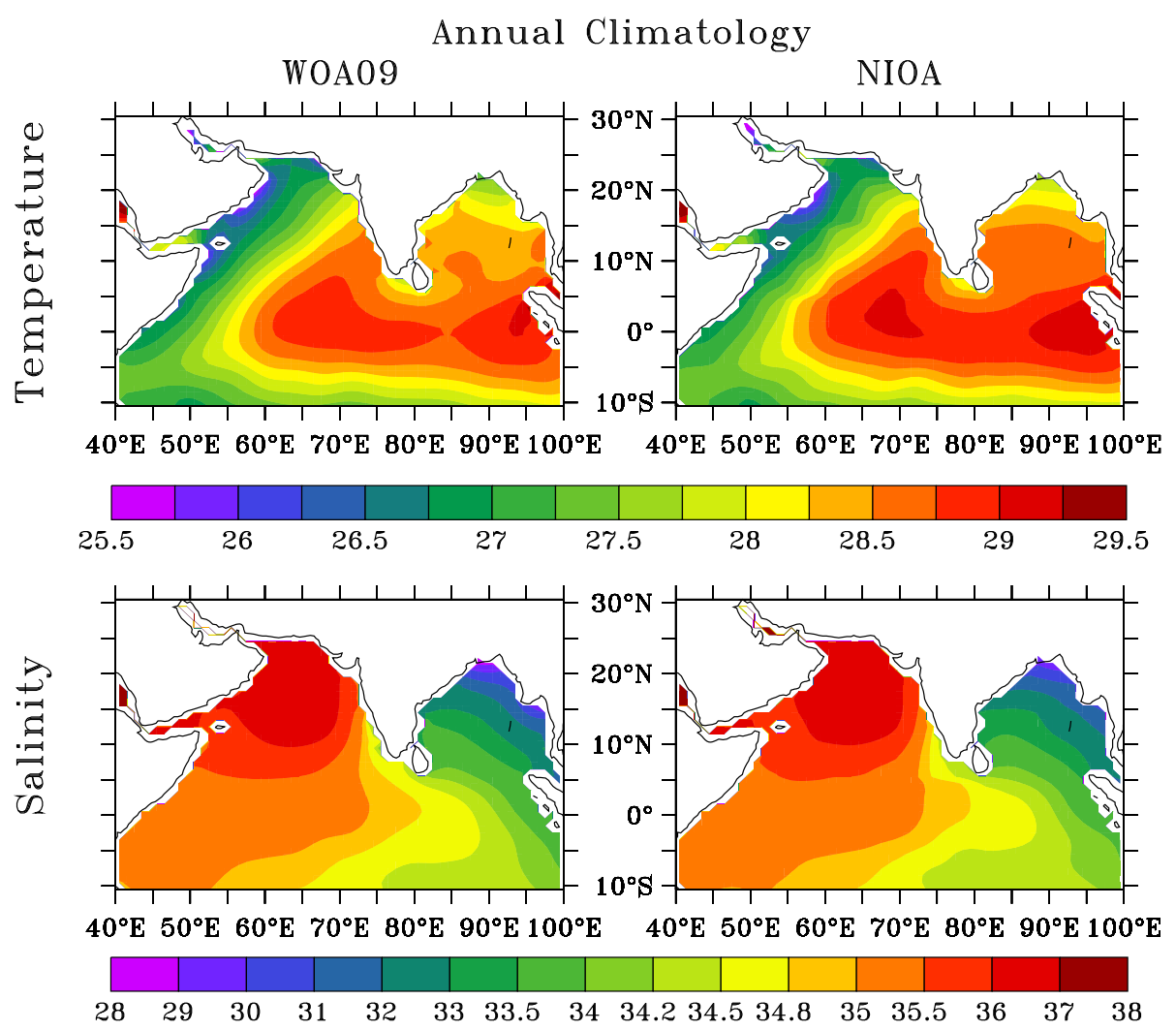

Figure 4. Comparison of annual surface temperature (top panels) and salinity (bottom panels) between WOA09 (left) and NIOA (right). Equatorial Indian Ocean and Bay of Bengal are $0.25^{\circ} \mathrm{C}$ warmer in NIOA than in WOA09. 
irrespective of year, and $X_{\mathrm{fg}}$ is the seasonal analysed climatology estimated in the previous step.

As done for the analysed annual and seasonal climatologies, the next step in the procedure is Barnes's interpolation (items $2-4$ in section 3.2.1). The resulting field constitutes the analysed monthly climatology.

\subsubsection{Final monthly climatology}

The analysed monthly climatology was filtered and smoothed to produce the final monthly climatology. A median filter and a Hanning-window filter
(Tukey 1974; Rabiner et al 1975) were applied first, followed by a five-point smoothing (Shuman 1957) (see Appendix B).

\subsubsection{Final seasonal and annual climatologies}

The next step was to estimate the seasonal and annual climatologies.

Top $1500 \mathrm{~m}$ : We first averaged the analysed monthly climatology corresponding to a given season to produce a re-analysed seasonal climatology. The filtering and smoothing operations applied
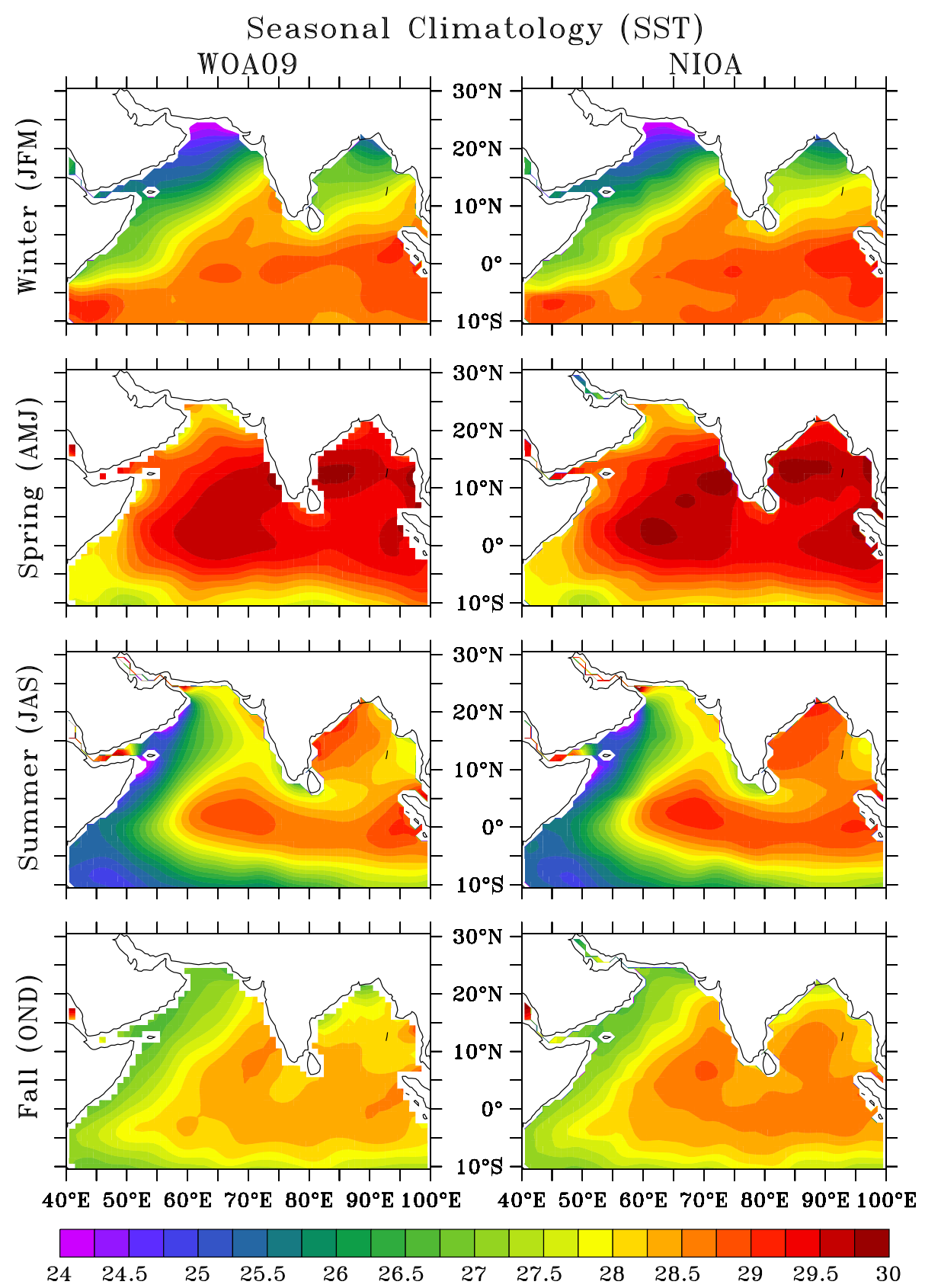

Figure 5. Comparison of seasonal surface temperature of WOA09 (left panels) and NIOA (right panels). 
earlier for the monthly climatology were now applied to this analysed seasonal climatology to produce the final seasonal climatology.

Likewise, the analysed monthly climatology was averaged over all 12 months to produce a re-analysed annual climatology. Filtering and smoothing this analysed annual climatology led to the final annual climatology.

These seasonal and annual climatologies were available only to a depth of $1500 \mathrm{~m}$ because the monthly climatology does not exist below this depth. Hence, the seasonal and annual climatologies below $1500 \mathrm{~m}$ had to be estimated separately.
Below 1500 m: For depth levels below $1500 \mathrm{~m}$, the analysed seasonal climatology (section 3.2.2) was first averaged to get an analysed annual climatology, which served as the first-guess field, $X_{\mathrm{fg}}$, for estimating a seasonal climatology. The observed seasonal mean field was used for $X_{\mathrm{om}}$. The next step was application of Barnes's interpolation method to produce an analysed seasonal climatology. Filtering and smoothing this analysed climatology led to the final seasonal climatology below $1500 \mathrm{~m}$.

The analysed seasonal climatology produced above (before filtering and smoothing) was
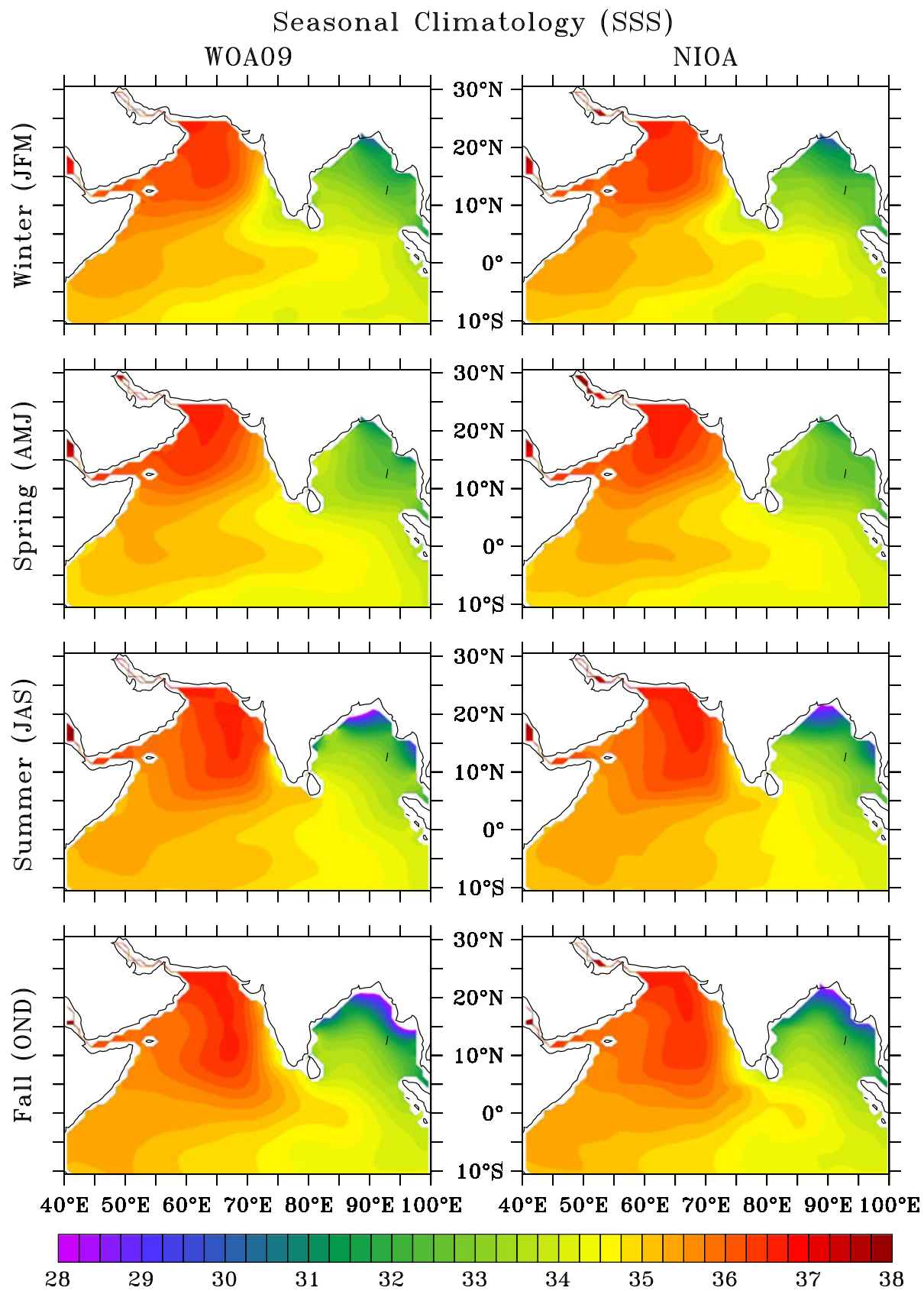

Figure 6. Comparison of seasonal surface salinity of WOA09 (left panels) and NIOA (right panels). 
averaged to get the analysed annual climatology. Filtering and smoothing this analysed climatology led to the final annual climatology below $1500 \mathrm{~m}$.

\subsection{Post-objective-analysis quality control}

After the initial objective analysis leading to the monthly, seasonal, and annual climatologies, additional checks were performed to identify unrealistic features. Such features are occasionally seen in data-sparse regions and are usually produced by one or more anomalous profiles. To eliminate these features, all the profiles from such areas were examined again to check for the data that were outliers. These data were flagged out and the entire procedure was repeated using the rectified data.

\section{Results}

The objectively analysed temperature and salinity fields in the North Indian Ocean Atlas from WOA09. As expected, the improvement was more for salinity than for temperature, and the improvement was restricted to the regions in which there was addition of new data: the Bay of Bengal and the eastern Arabian Sea. We present some of the major improvements in this section.

\subsection{Annual climatology}

The annual WOA09 and NIOA climatologies look largely the same (figure 4), except for the following differences: the northern Bay of Bengal is 0.25$0.5^{\circ} \mathrm{C}$ warmer in NIOA, the Indian Ocean warm pool (Joseph 1990; Vinayachandran and Shetye

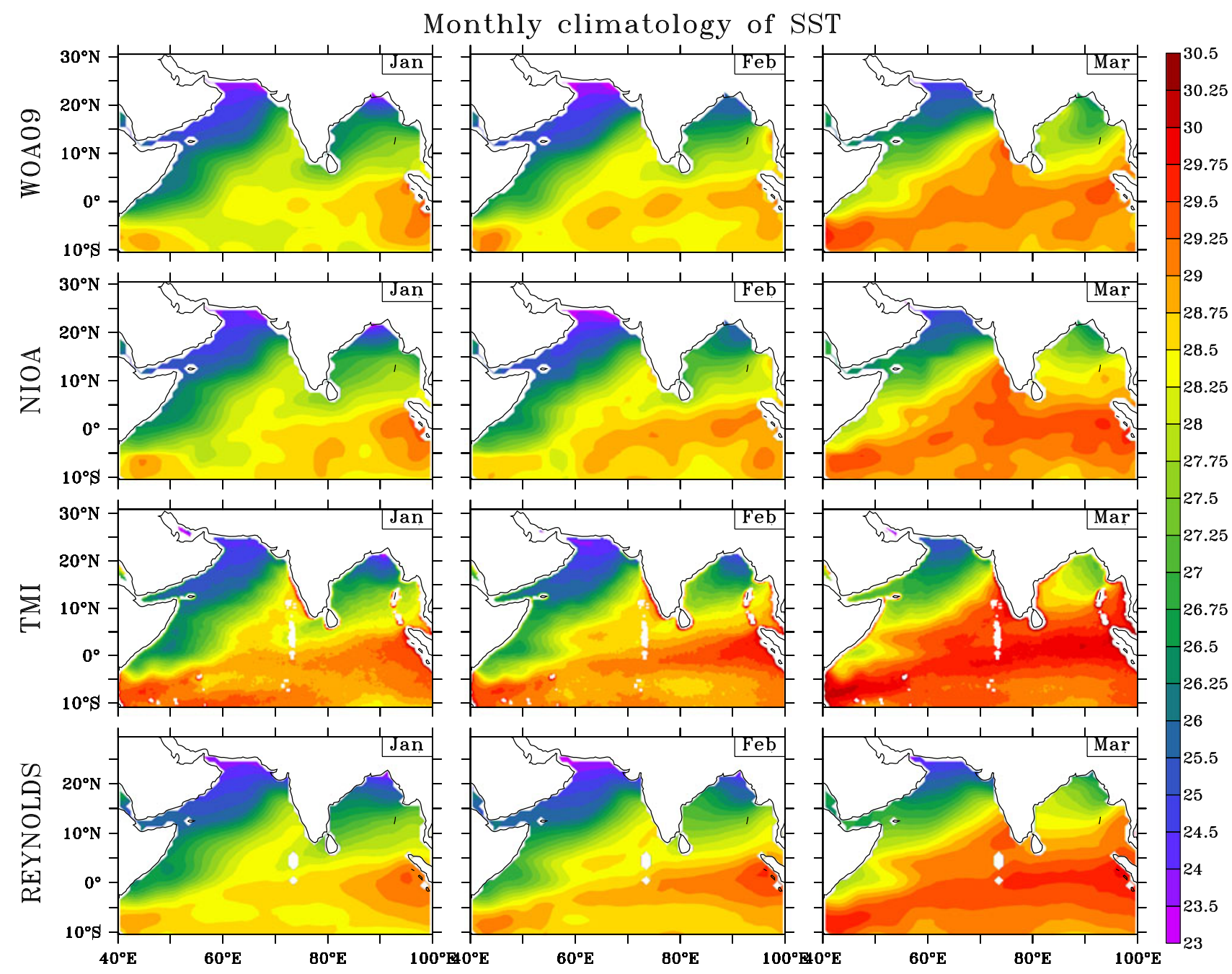

Figure 7. Comparison of monthly surface temperature between WOA09 (top panels; Locarnini et al 2010; Antonov et al 2010), NIOA (upper middle panels), TMI (lower middle panels; available at http://www.ssmi.com/tmi/tmi_browse.html) and REYNOLDS (bottom panels; Reynolds et al 2002). Owing to sparsity of data, several patches of high and low temperatures are seen in WOA09. In NIOA, such patches are either removed or considerably weakened. 


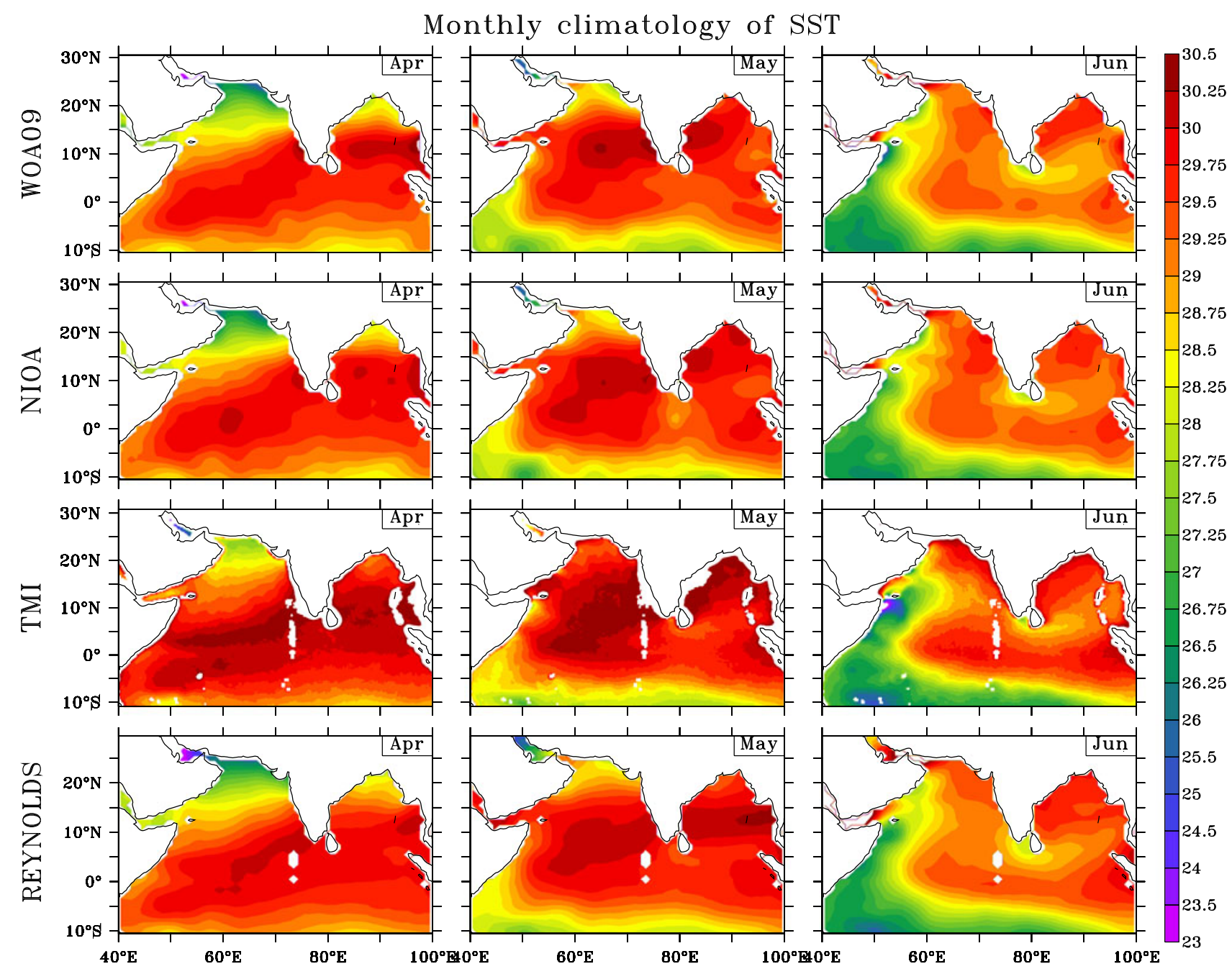

Figure 7. (Continued)

1991 ) is also $0.25^{\circ} \mathrm{C}$ warmer in NIOA, and the low-salinity water in the southeastern Arabian Sea (SEAS) (Wyrtki 1971; Antonov et al 2010) spreads more westward or offshore in NIOA compared to WOA09, in which it penetrates more poleward along the Indian west coast.

\subsection{Seasonal climatology}

The seasonal changes of temperature follow the movement of the Sun in both WOA09 and NIOA (figure 5), but a large fraction of the equatorial Indian Ocean is about $0.25^{\circ} \mathrm{C}$ warmer in NIOA in all seasons. In spring, the Arabian Sea miniwarm-pool (Rao and Sivakumar 1999; Shenoi et al 1999) and warm eastern equatorial ocean are more evident in NIOA.

Likewise, the seasonal changes of salinity are similar in both WOA09 and NIOA (figure 6). The seasonal evolution of salinity is more subtle and the differences between the two climatologies are more evident in the monthly climatologies.

\subsection{Monthly climatology}

The surface temperature and salinity fields from WOA09 and NIOA are shown for all months in figures 7 and 8. Figure 7 also includes comparison with the surface temperature measured by the TRMM (Tropical Rainfall Measuring Mission) Microwave Imager (TMI) satellite (available at http://www.ssmi.com/tmi/tmi_description.html) and surface temperature based on the 'Reynolds SST dataset' (Reynolds et al 2002). Figure 8 includes a comparison with the salinity climatology of Ishii et al (2005). Figure 9 shows the number of profiles used for the monthly climatologies of surface temperature and salinity.

\subsubsection{Surface temperature}

One major improvement seen in NIOA is the elimination of several patches of high and low temperature seen in WOA09 during several months in the Bay of Bengal, particularly along the Indian east coast (figure 7); these patches are due to 


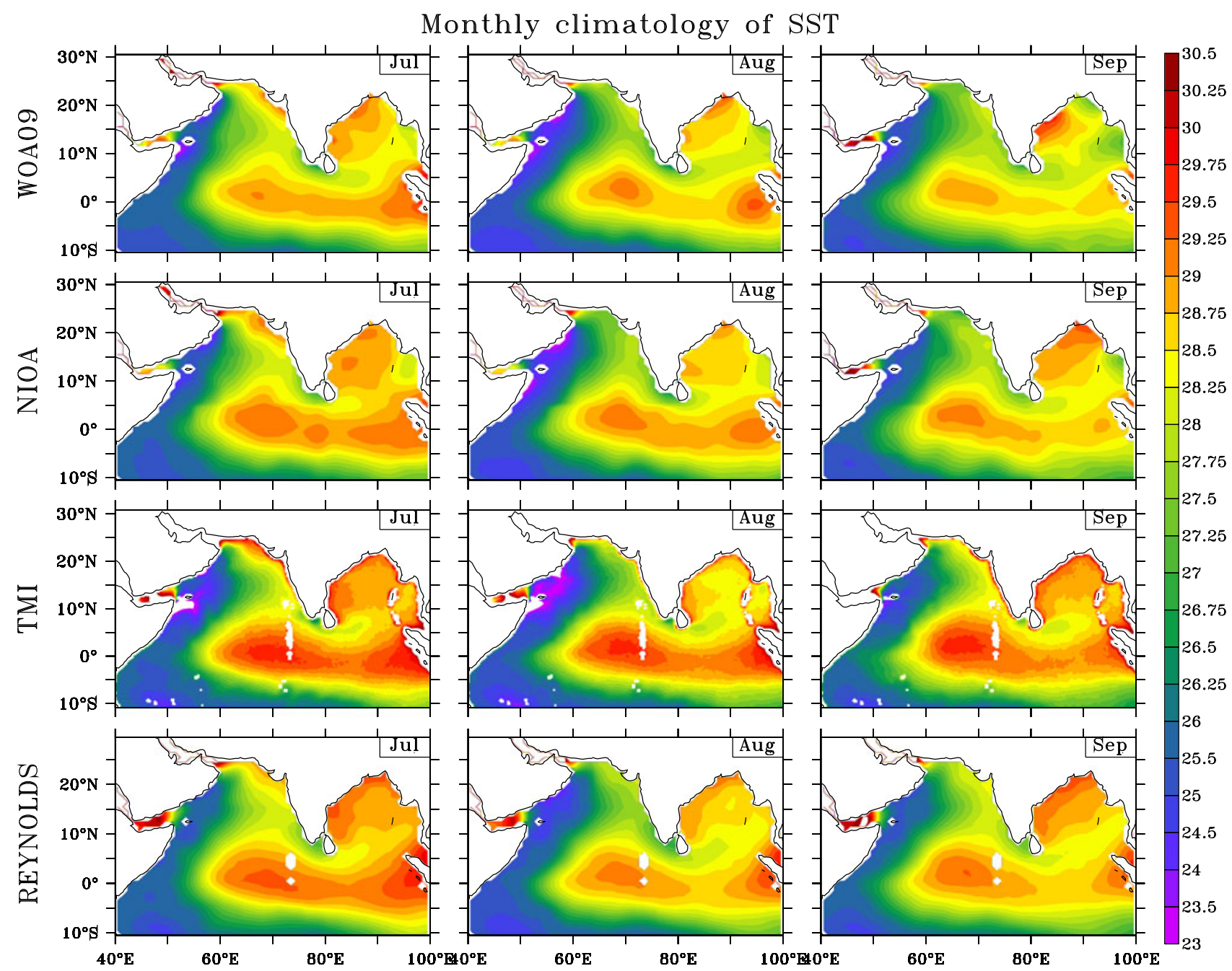

Figure 7. (Continued)

noise that remains in the Levitus climatologies in spite of smoothing and is particularly evident in the data-sparse Bay of Bengal (figure 9). This improvement in NIOA was most significant during the summer monsoon. The prevalence of these patches in the monthly climatology in WOA09 led to such a patch even in the annual climatology (figure 4).

The other significant improvement in NIOA was in the northern Bay of Bengal, which did not cool as much in WOA09 following the summer monsoon (figure 7); in December, the northern bay was $1^{\circ} \mathrm{C}$ warmer in NIOA and other satellite-derived climatologies than in WOA09. Note, however, that TMI temperatures are higher than those in the climatologies based on hydrographic and Reynolds data. The temperature gradients evident in WOA09 owing to sparsity of data were smoothed out, leading to a more uniform temperature across the basin during and following the summer monsoon. The SEAS was also warmer during December-February in NIOA.
South of Sri Lanka, the cooling starts during May in NIOA, WOA09 also shows a similar signature, though weak compared to NIOA. The cold pool starts strengthening from June, and reaches its peak in August. The cold pool (Joseph et al 2005 ), which is a result of the eastward advection of the cold waters into the southern bay (Shankar et al 2002, 2007; Rao et al 2006a, 2006b), did not extend as far east as in WOA09.

\subsubsection{Surface salinity}

The addition of new data in NIOA eliminated lowsalinity and high-salinity patches off the east coast of India and a few patches in the eastern Bay of Bengal. Such patches occurred in WOA09 in several months (figure 8) due to the absence of data (figure 9); these patches were either completely eliminated in NIOA or were weakened considerably. An example is the elimination of the high-salinity patches seen in WOA09 between $14^{\circ}$ and $18^{\circ} \mathrm{N}$ during July (figure 8); similar patches appear in 


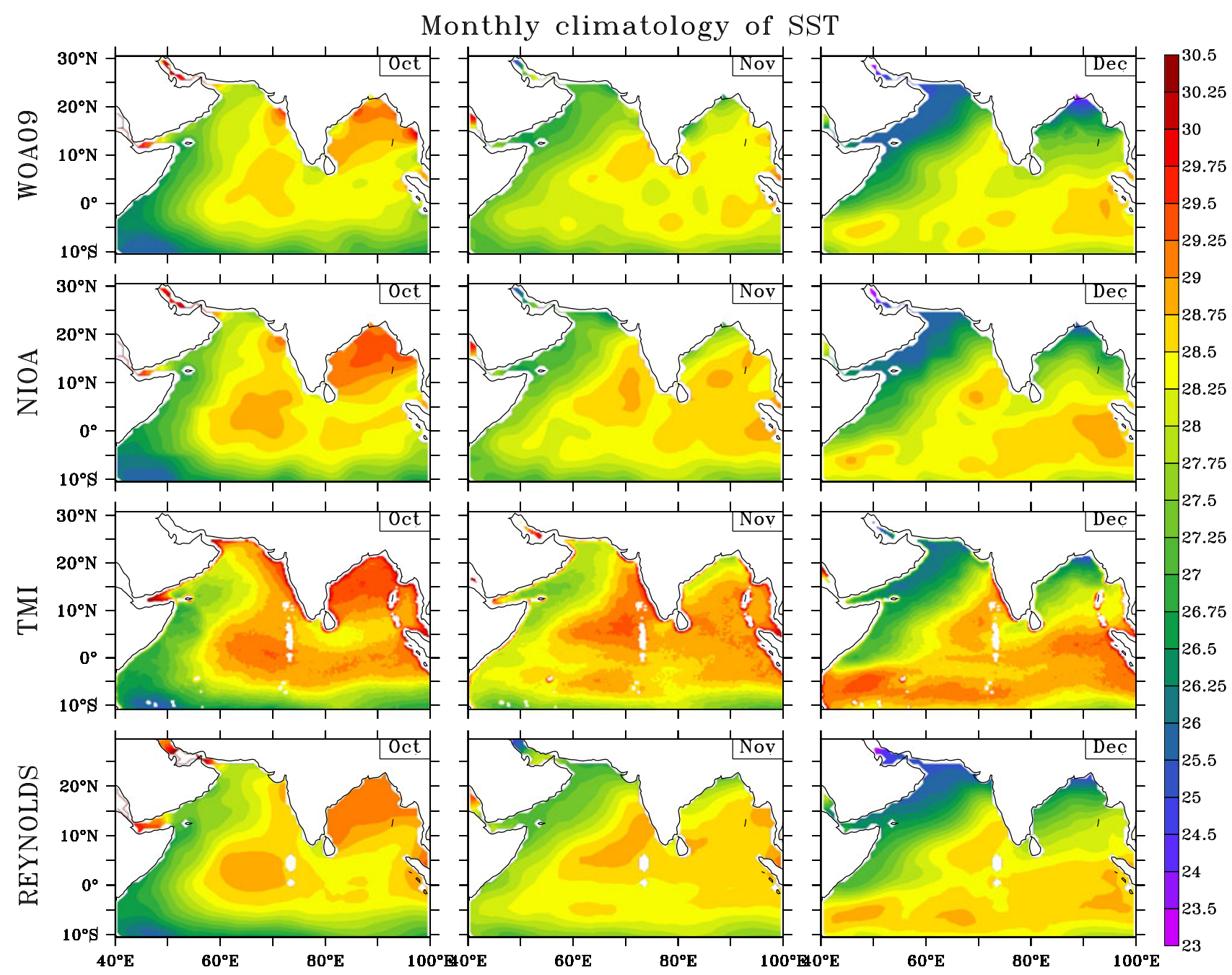

Figure 7. (Continued)

WOA09 for all the months. Similar patchiness is also seen in the climatology of Ishii et al (2005, 2006) (figure 8).

Several new profiles were added in the northern Bay of Bengal; profiles were also added in the eastern bay and Andaman Sea during February, May, June, September, October and December. These additional profiles precluded the need to extrapolate offshore salinity towards the coast, and the salinity in the northern and eastern bay and in the Andaman Sea was higher in NIOA during JuneDecember (figure 8), when the rainfall over the bay and freshwater inflow from rivers lower salinity in the region (Shetye 1993; Xie and Arkin 1997; Fekete et al 2002).

A similar increase in surface salinity is seen in NIOA during July-August in the SEAS owing to the addition of new data (figure 9).

The lowest salinity in the SEAS occurs during the winter monsoon (November-February) (Wyrtki 1971; Antonov et al 2010). This low salinity is a consequence of inflow of fresher water from the
Bay of Bengal (Shetye et al 1991, 1996; Shetye 1993; Rao and Sivakumar 1999; Shenoi et al 1999; Han and McCreary 2001; Durand et al 2004, 2007; Kurian and Vinayachandran 2007). In November, when the low-salinity water enters the SEAS from the Bay of Bengal, the poleward penetration, along the west coast, of this low-salinity water is greater in NIOA than in WOA09 (figure 8). Subsequently, from December-March, however, this low-salinity water does not penetrate as far north in NIOA as in WOA09 (figure 8) or in the earlier versions of the Levitus climatology. In NIOA, the freshwater spreads more offshore or westward than poleward along the coast as in WOA09.

\subsubsection{Subsurface temperature and salinity}

Compared to the change at the surface, there was less change in temperature from WOA09 to NIOA at depths below 200-250 m. At $100 \mathrm{~m}$, in the Bay of Bengal, the additional data helped eliminate low and high-temperature patches along the 


\section{Monthly climatology of SSS}
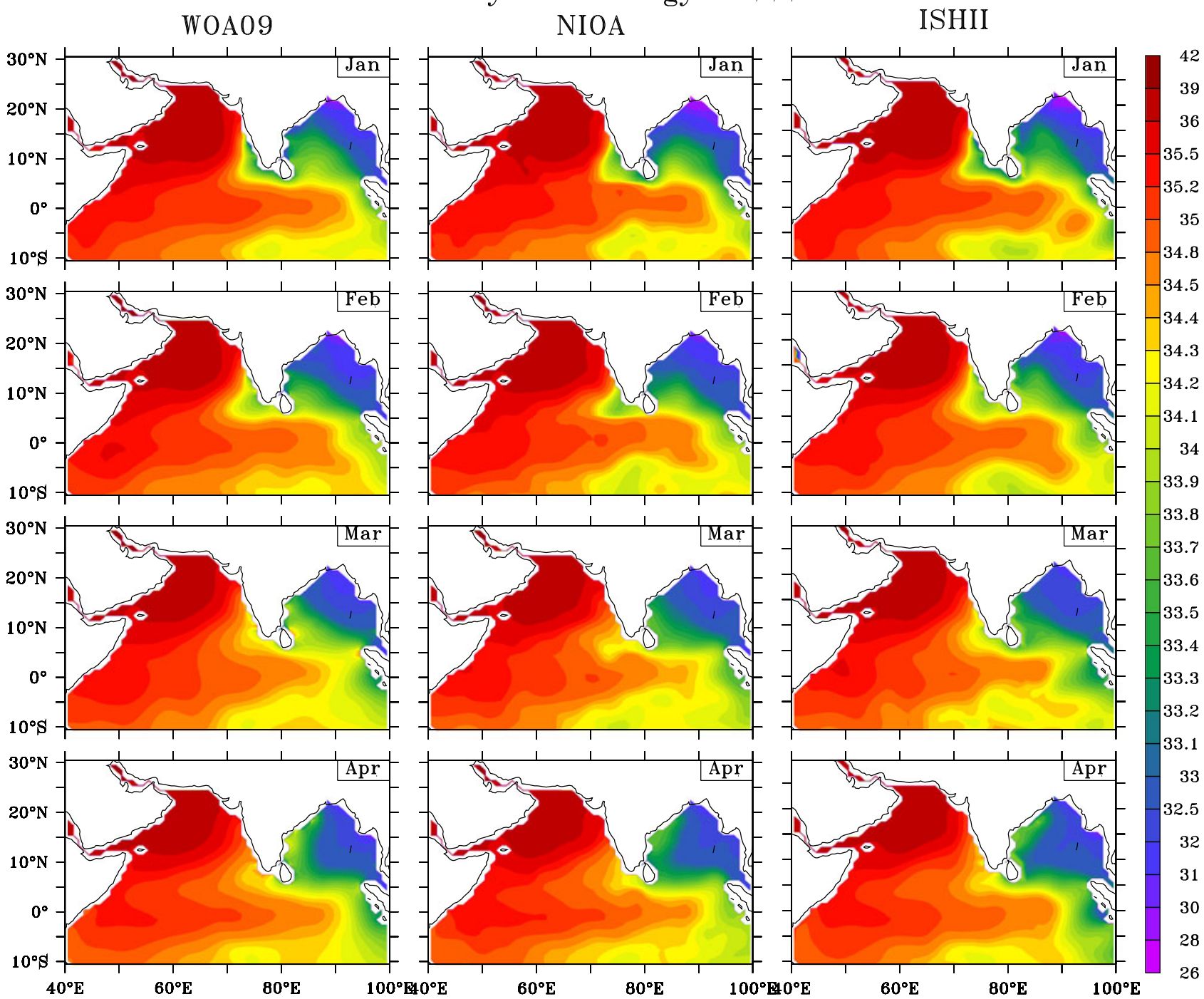

Figure 8. Comparison of monthly surface salinity between WOA09 (left panels; Locarnini et al 2010; Antonov et al 2010), NIOA (centre panels) and ISHII (right panels; Ishii et al 2005, 2006). Addition of data in NIOA eliminates the high and low-salinity patches seen in WOA09 along the east coast of India.

Indian east coast (figure 10). The spring warming in the SEAS (McCreary et al 1993; Bruce et al 1994; Shankar and Shetye 1997; Rao and Sivakumar 1999; Shenoi et al 1999; Durand et al 2004; Kurian and Vinayachandran 2007) penetrates farther poleward along the coast in NIOA (figure 10).

The impact on salinity was also less at, say, $100 \mathrm{~m}$ than at the surface, but patches of high and low salinity, which were evident in WOA09 even at subsurface levels, were eliminated in NIOA. A more significant improvement in the horizontal subsurface maps resulting from the new data, however, was the smoother change in the salinity climatology of the Bay of Bengal from month to month. The abrupt changes seen in WOA09 were eliminated by the additional data. Figure 11 shows, for example, the improvement at $100 \mathrm{~m}$ during April-July.

\subsubsection{Vertical sections}

Vertical sections taken roughly along the $200 \mathrm{~m}$ isobath off the Indian coasts show a significant improvement in NIOA. The contours were smoother in NIOA than in WOA09. For both temperature and salinity, patchiness, as in the horizontal sections, were either eliminated or considerably weakened (figures 12-14). Sharp gradients and sharp features seen in WOA09 were either eliminated or smoothed considerably. These gradients must have occurred due to the coarse sampling in WOA09. Such gradients and features can occur when a grid has only one profile that caught the different phase 


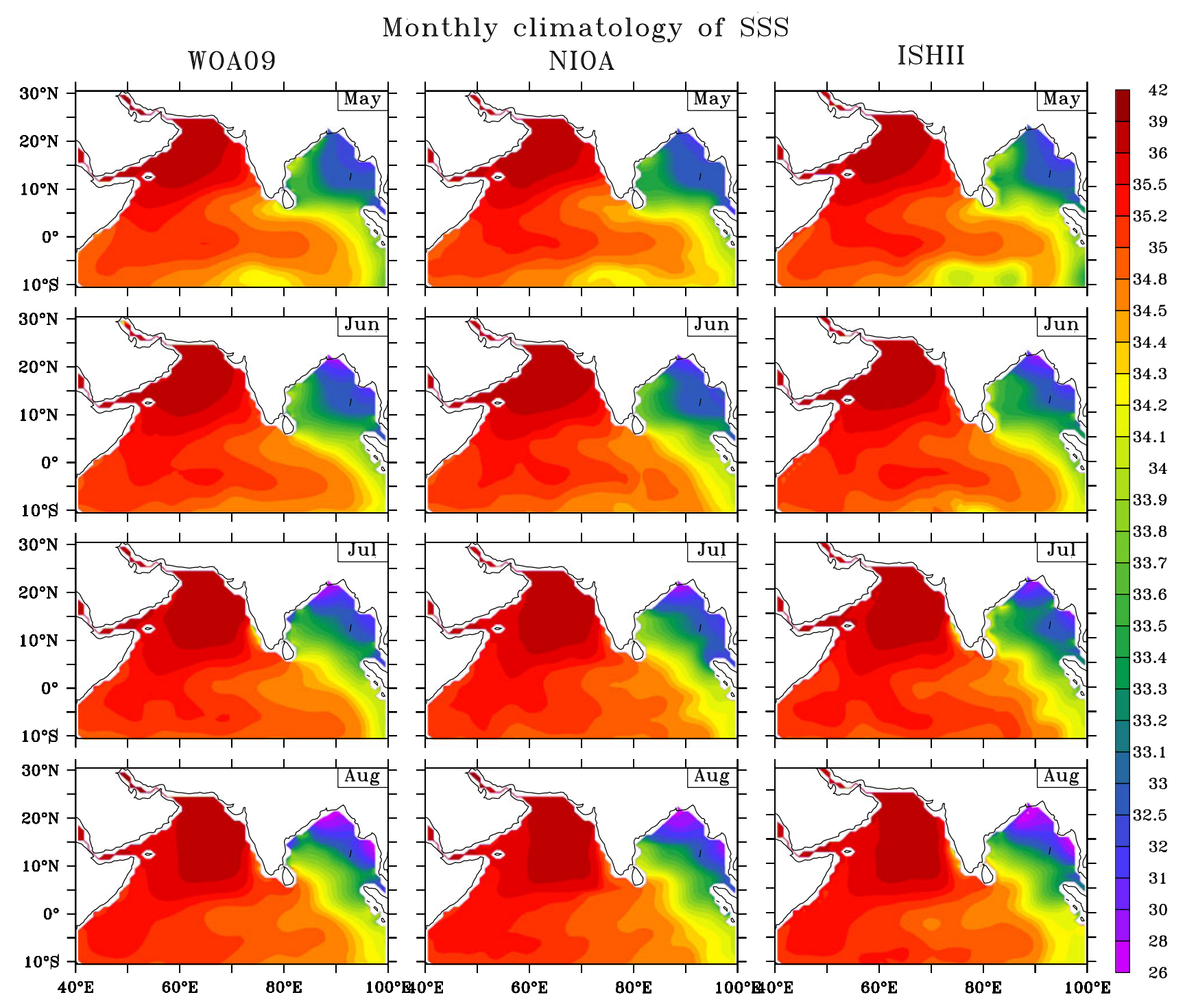

Figure 8. (Continued)

of the internal waves than the phases represented in the surrounding grids. The addition of several new profiles in NIOA facilitated averaging across the internal-wave phases and eliminated and smoothed the gradients of temperature and salinity considerably. This improvement is more evident in the Bay of Bengal than in the Arabian Sea because the NODC database, used in the preparation of WOA09, had more data off the Indian west coast.

The addition of new data in NIOA also brings out clearly the equatorward movement of freshwater along the Indian east coast following the summer monsoon (figure 13), and its poleward movement along the Indian west coast during the winter monsoon (figure 14). The low-salinity water of Bay of Bengal origin overlies the denser Arabian Sea-High-Salinity-Water (ASHSW) (Rochford 1964; Shenoi et al 1993) in the eastern Arabian Sea. As seen earlier at the surface (figure 8), the low-salinity water does not penetrate as far poleward along the coast in NIOA as in WOA09 (figure 14).

\subsection{Quantifying improvement in the climatology}

The comparisons between WOA09 and NIOA show qualitative improvements in the latter. To quantify this improvement, we require a standard against which to test the two climatologies. In the absence of any obvious standard for comparison - the climatology itself provides a reference standard for several studies, with models often restoring salinity, in particular, to the climatological value to reduce model drift -, we chose the observed mean as a standard for the temperature or salinity in a grid cell. Grid cells with less than five observed profiles were excluded from 


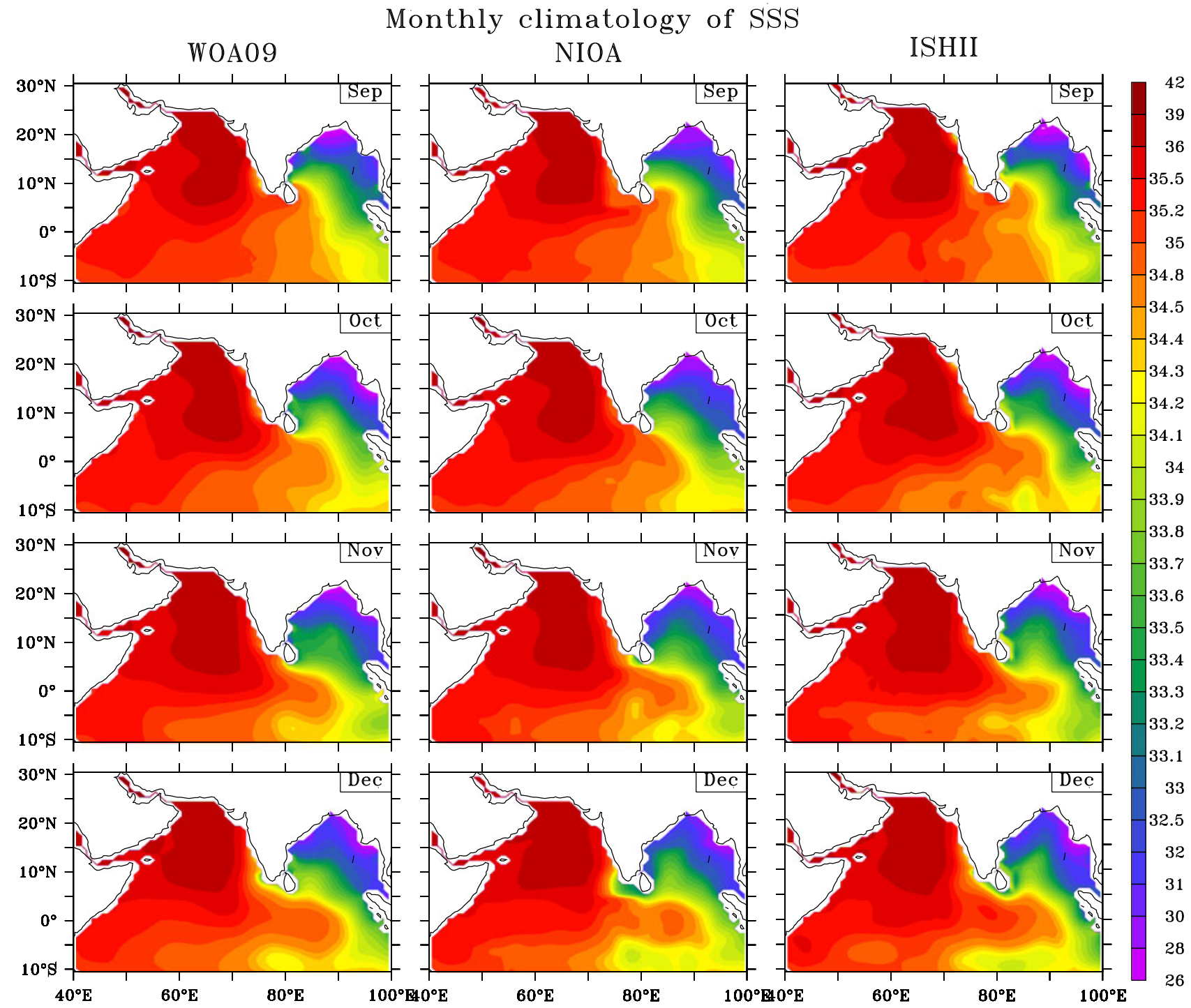

Figure 8. (Continued)

this comparison. The goodness of the climatology is then measured by the deviation from this mean: the lower the deviation, the better the climatology. The measure used was the significance of the difference between each of the climatologies and the observed mean over different regions. This significance was estimated using the Welch's $t$-test, which estimates the similarity of two datasets by considering their variance. A large $t$ value implies that the two datasets are not similar. This test was performed for each depth level separately and a $t$ value was estimated for different regions (figure 15).

The results show that the temperature in NIOA is statistically closer to the observed mean even when the entire basin is considered; the improvement in NIOA over WOA09 is, however, much greater in the Bay of Bengal, as suggested by the qualitative comparison presented earlier.
For salinity, the large gradient in the nearsurface levels along the east coast implies a large variance over the grid cells in this part of the Indian EEZ. Hence, if the region covers the entire Indian east coast, the variance is comparable to the mean, leading to a breakdown of a key assumption in the Welch's $t$-test, and no improvement is seen in NIOA over WOA09. When the region is restricted to the northern part of the EEZ, the variance decreases, and the improvement in NIOA is obvious.

\section{Discussion}

\subsection{Climatology with redefined seasons}

Levitus defined the season (see section 3.2.2) to represent the seasons over the globe as a whole. The NIO is however, dominated by the monsoonal 


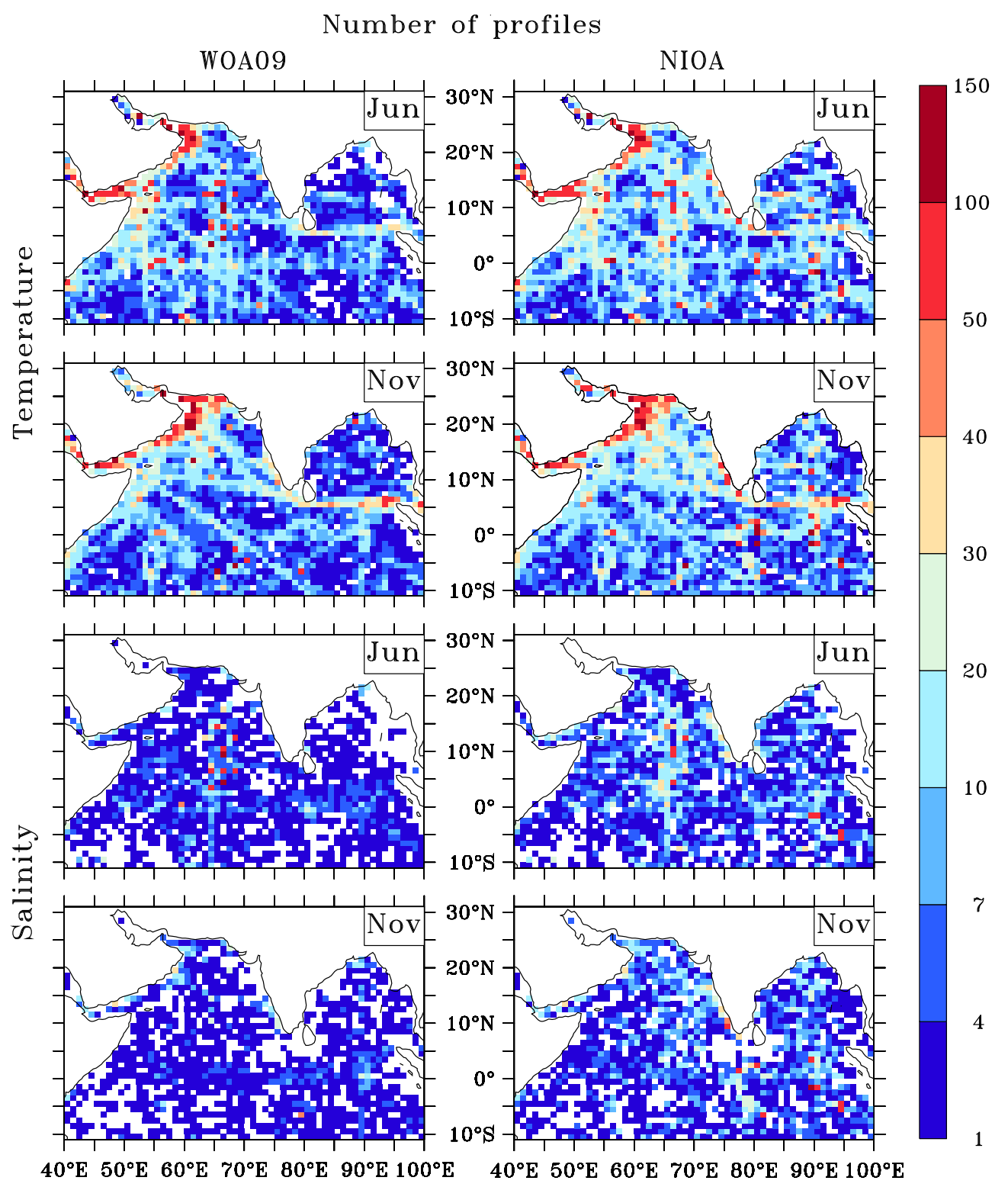

Figure 9. Comparison of number of profiles used for the monthly surface temperature and salinity between WOA09 (left) and NIOA (right). Northern Bay of Bengal is a data-void region in WOA09, but addition of data from Indian sources in NIOA filled most of the data-void grids in this region.

cycle and experiences the summer (or southwest) monsoon during June-September and the winter (or northeast) monsoon during DecemberFebruary. As a result, several studies of this region prefer to divide the year into seasons different from that used by Levitus, a typical division consisting of winter, spring intermonsoon or transition, summer monsoon, and post-monsoon or fall intermonsoon. Hence, we redefined the Levitus seasons to suit the variability in this region. The four seasons we considered are as follows.

1. Winter monsoon: December-January-February 2. Spring intermonsoon: March-April-May

3. Summer monsoon: June-July-August-September

\section{Fall intermonsoon: October-November}

What is the impact of this redefinition of the seasons on the monthly climatology? To answer this question, we repeated the procedure outlined in section 3.2 using the new monsoonal definition of seasons. Surprisingly, there was almost no difference between the monthly climatologies derived using the two definitions of seasons and with the Levitus definition of season (figure not shown). The zonal interpolation eliminates any influence of the first guess field, the seasonal analysed values.

How different are the annual climatologies derived using the two definitions of the seasons? 
Temperature at $100 \mathrm{~m}$ depth

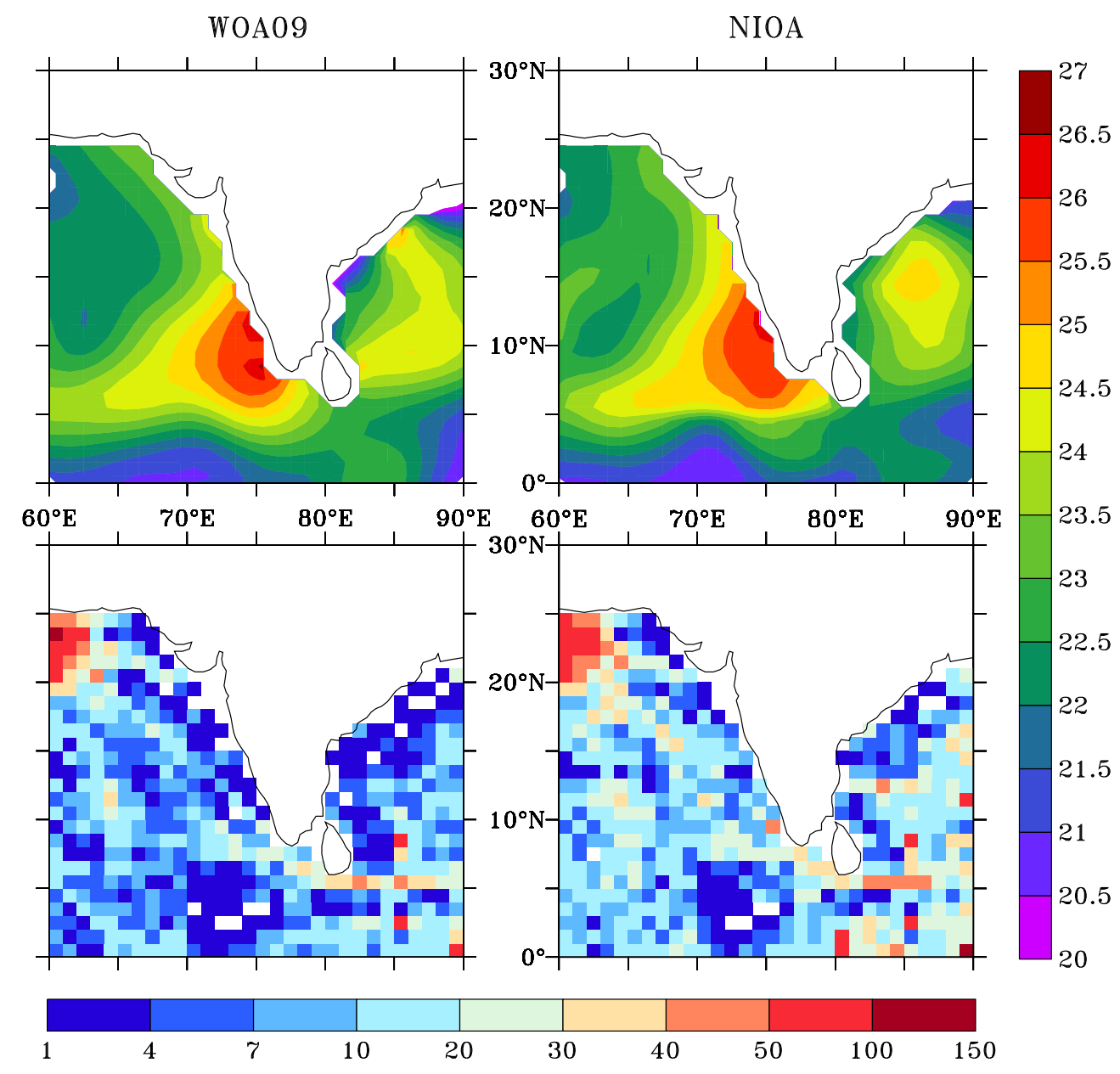

Figure 10. Comparison of temperature at $100 \mathrm{~m}$ (top panels) between the WOA09 (left) and NIOA (right) and the number of profiles used (bottom panels) during February. The spring warming in SEAS penetrates further poleward in NIOA at $100 \mathrm{~m}$.

To answer this question, we completed the procedure described in section 3.2 to derive an annual climatology based on the new monsoonal definition of seasons. Since the annual climatology was the average of all 12 monthly climatologies, there was no difference between the annual climatologies derived using new definition of seasons and using Levitus definition of seasons for the upper $1500 \mathrm{~m}$. A comparison between the two climatologies is shown in figure 16.

Since some users may prefer to use a seasonal climatology with the new data included, but with the new monsoonal definition of seasons, which is more appropriate for the NIO, we derived another seasonal climatology following the procedure outlined in section 3.2 , but using the new definition of seasons. The surface temperature and salinity fields from this climatology are shown in figure 17. (This seasonal climatology should be compared with the seasonal climatologies in WOA09 and NIOA (figures 5 and 6).)
The new definition of seasons, however, shows more clearly the warm pool preceding the summer monsoon (Joseph 1990; Vinayachandran and Shetye 1991) and the two warm areas that exist during the summer monsoon, i.e., in the equatorial Indian Ocean and the northern Bay of Bengal (Sikka and Gadgil 1980; Gadgil and Srinivasan 1990). Furthermore, the cold pool in the southern Bay of Bengal (Joseph et al 2005; Rao et al 2006a, $2006 \mathrm{~b}$ ) and its restriction to the western half of the southern bay (Shankar et al 2007), which is in accordance with satellite measurements, is evident in the NIOA seasonal climatology for the summer monsoon. This restriction of the cold pool to the southwestern bay is in accordance with satellite measurements of SST (Shankar et al 2007).

The inclusion of December in winter leads to a lower salinity in the northern bay in the monsoonaldefinition climatology (figure 17) compared to NIOA (figure 6). The changes in the other seasons are more subtle. 


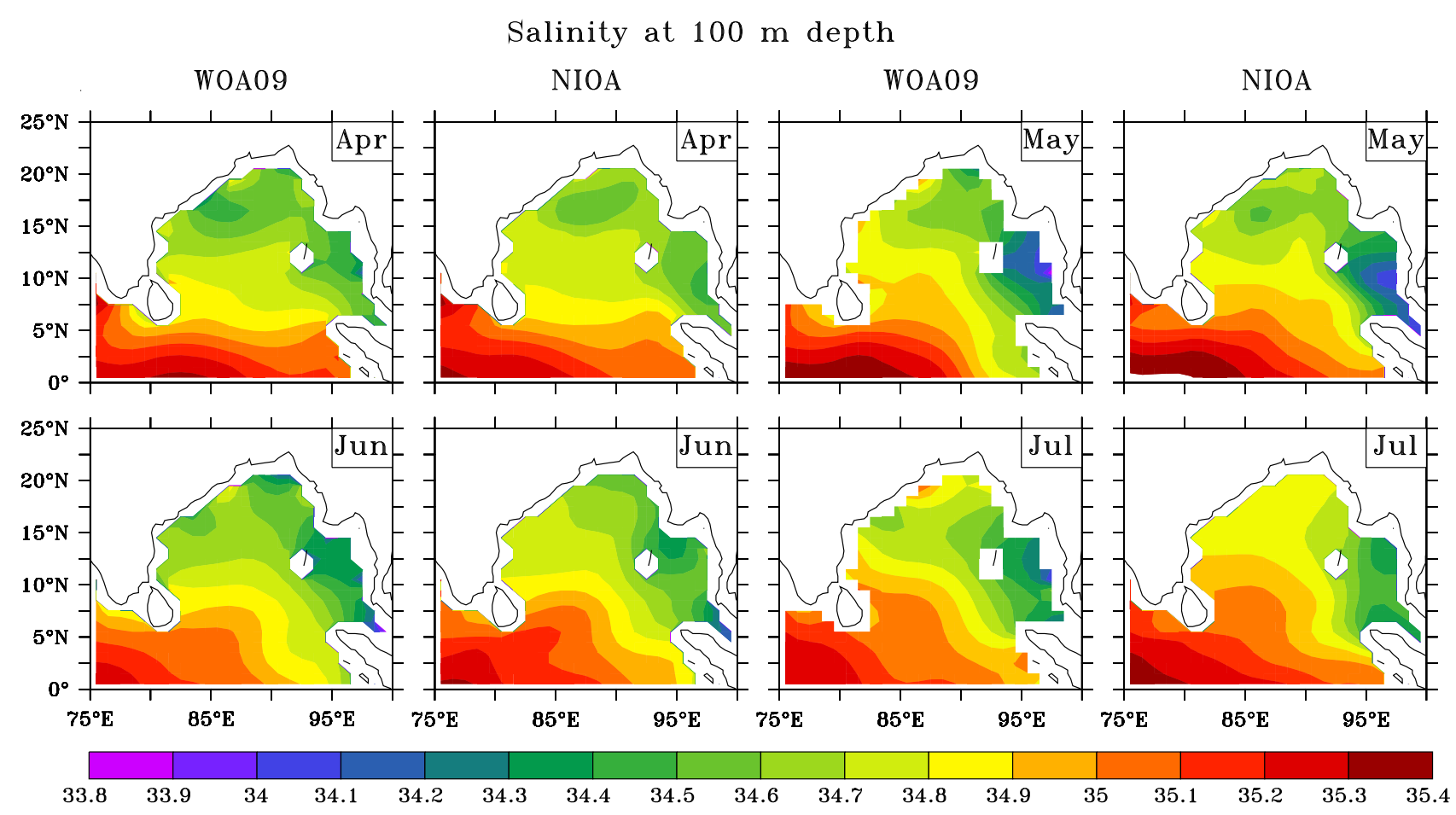

Figure 11. Comparison of salinity at $100 \mathrm{~m}$ between WOA09 (left panels) and NIOA (right panels) for the Bay of Bengal during April to July. The change in time is smoother in NIOA than in WOA09, which shows abrupt changes.

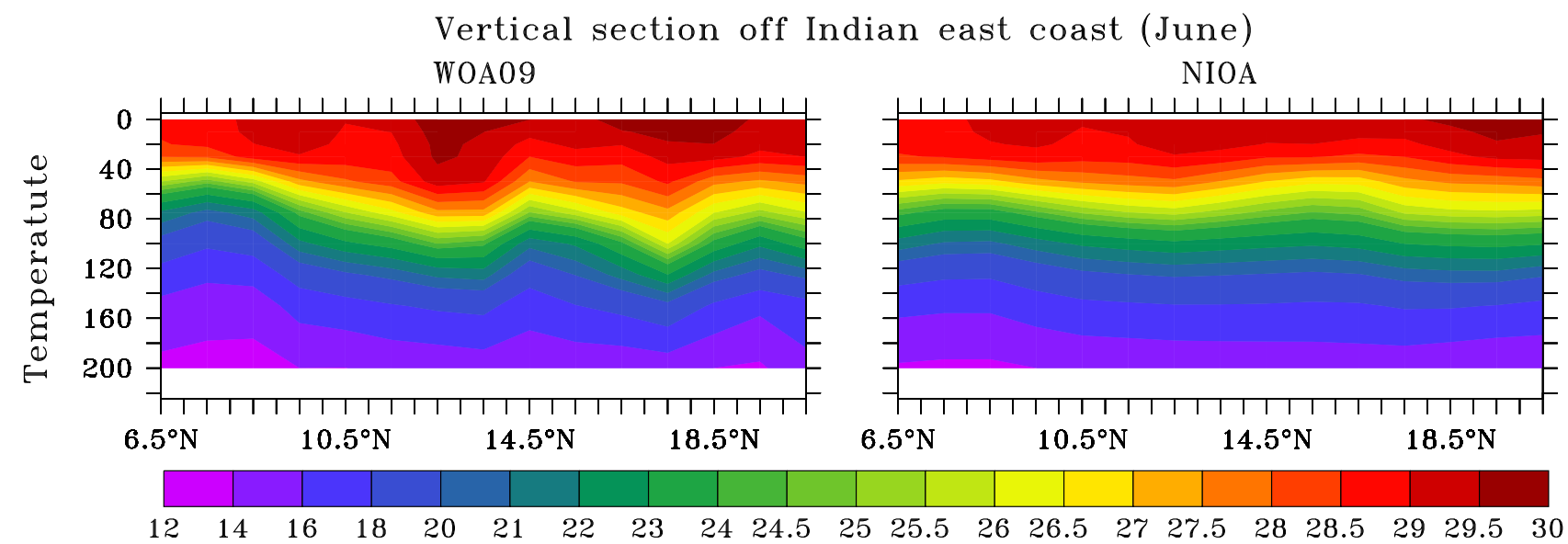

Figure 12. Comparison of vertical sections of temperature between WOA09 (left panel) and NIOA (right panel) off the east coast of India along roughly the $200 \mathrm{~m}$ isobath during June. The abscissa gives the latitude and the ordinate gives the depth. Note the elimination, in NIOA, of the patches that are evident in WOA09, and the smoother contours in NIOA.

\subsection{Comparison with other methods}

The method we followed to derive the climatologies described in section 4 was the one used in WOA05. We also tried other methods, including the one used in WOA09. A brief discussion of these methods and the results is given below.

\subsubsection{World Ocean Atlas 2009}

In WOA09, Locarnini et al (2010) and Antonov et al (2010) introduced a change in the procedure after the creation of the analysed monthly climatology in section 3.2.3. Until this step, the data for creating the analysed climatologies, whether, annual, seasonal, or monthly, were averaged irrespective of year, as in WOA05. In WOA09, however, an additional step was introduced at this point: the analysed monthly climatologies, derived using all the data available, were used as first-guess fields for creating decadal monthly climatologies. In deriving the monthly climatology for each decade (1955-1964, 1965-1974, 19751984, 1985-1994 and 1995-2006), only the data 


\section{Vertical section of salinity along Indian east coast} WOA09

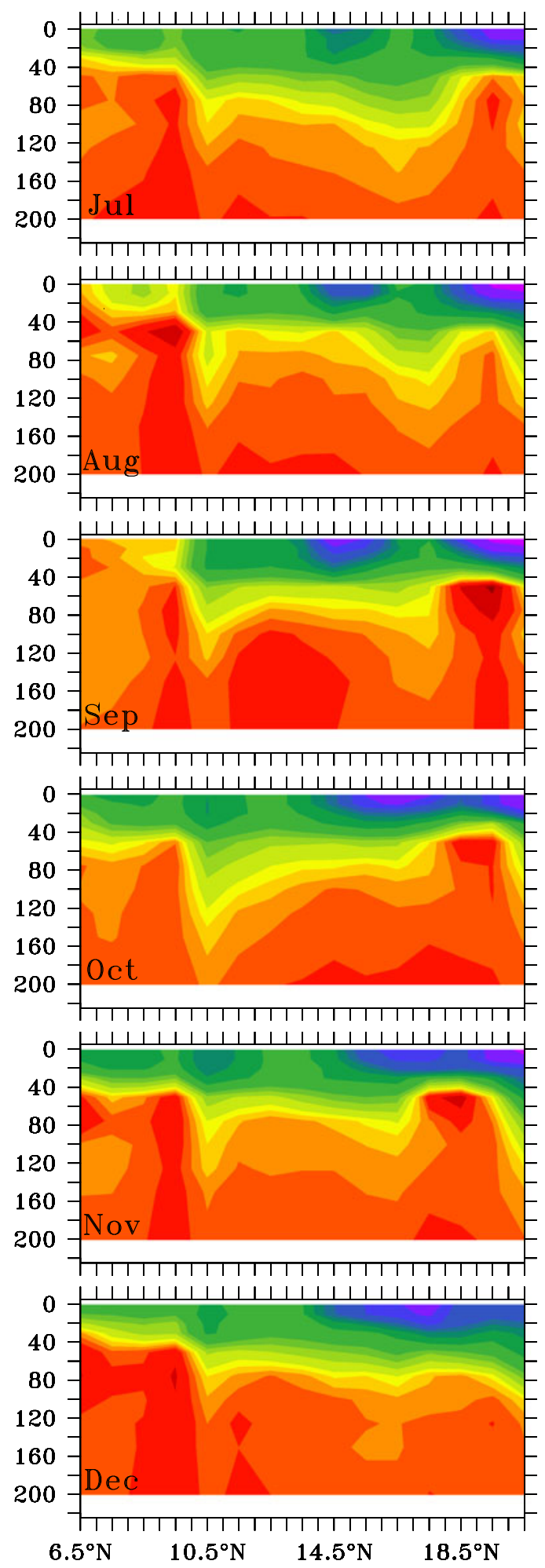

NIOA

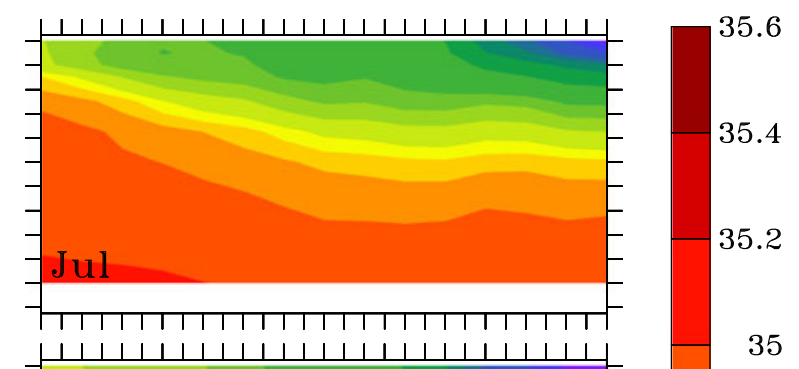

34.9

34.8

34.7

34.6

34.4

34.2

34

33.5

33

32.5

32

31

30

28

26

Figure 13. Comparison of vertical sections of salinity along roughly the $200 \mathrm{~m}$ isobath in the Bay of Bengal (off the Indian east coast) between WOA09 (left panels) and NIOA (right panels) during July-December. Note the smoother equatorward movement of fresher water in NIOA. 

Vertical section of salinity along Indian west coast
WOA09
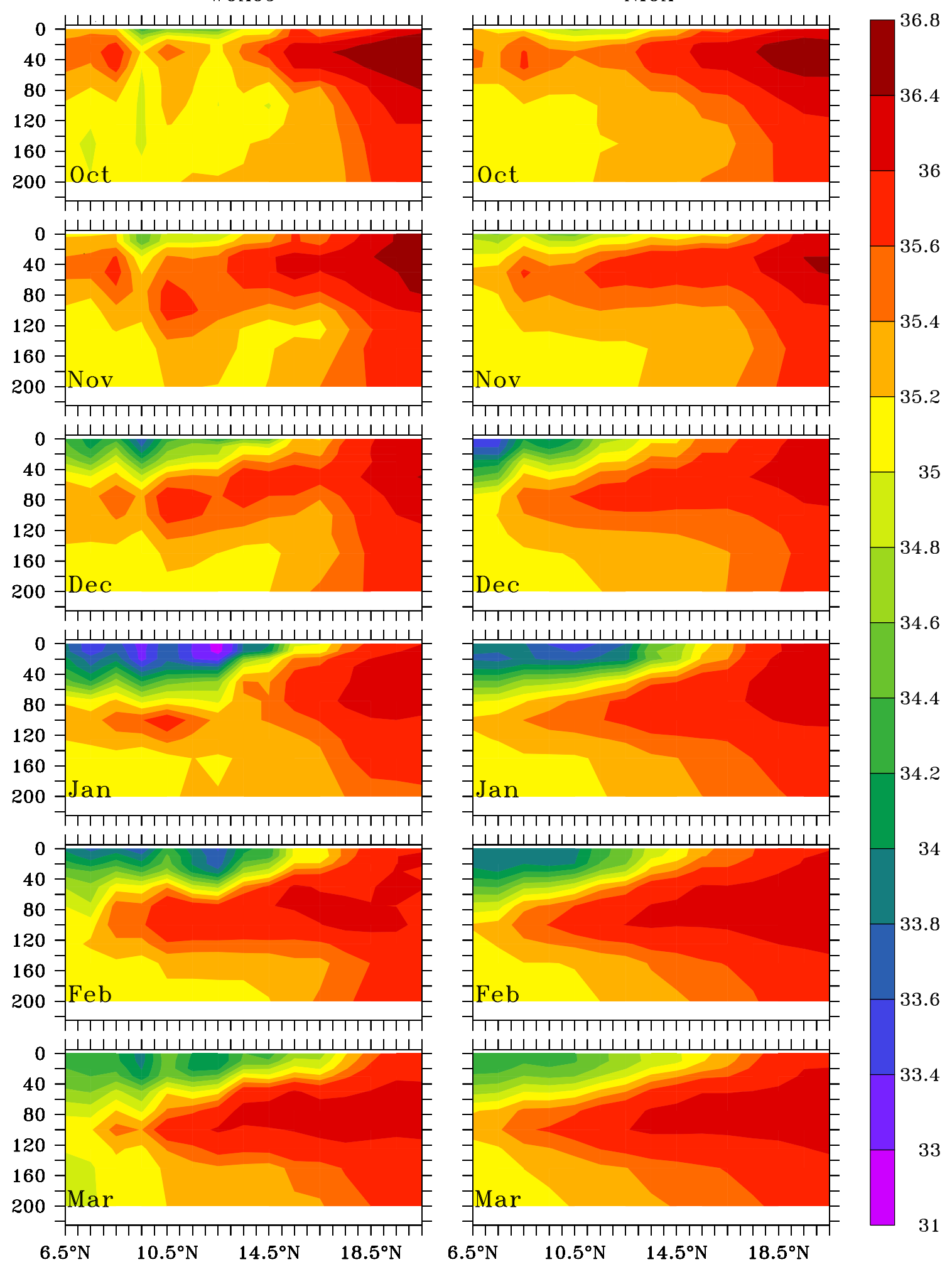

Figure 14. Comparison of vertical sections of salinity along roughly the $200 \mathrm{~m}$ isobath in the Arabian Sea (off the Indian west coast) between WOA09 (left panels) and NIOA (right panels) during October-March. Note the smoother poleward movement of fresher water, of Bay-of-Bengal origin, in NIOA; this low-salinity water moves over the denser ASHSW. 


\section{Welch's $t$-test}
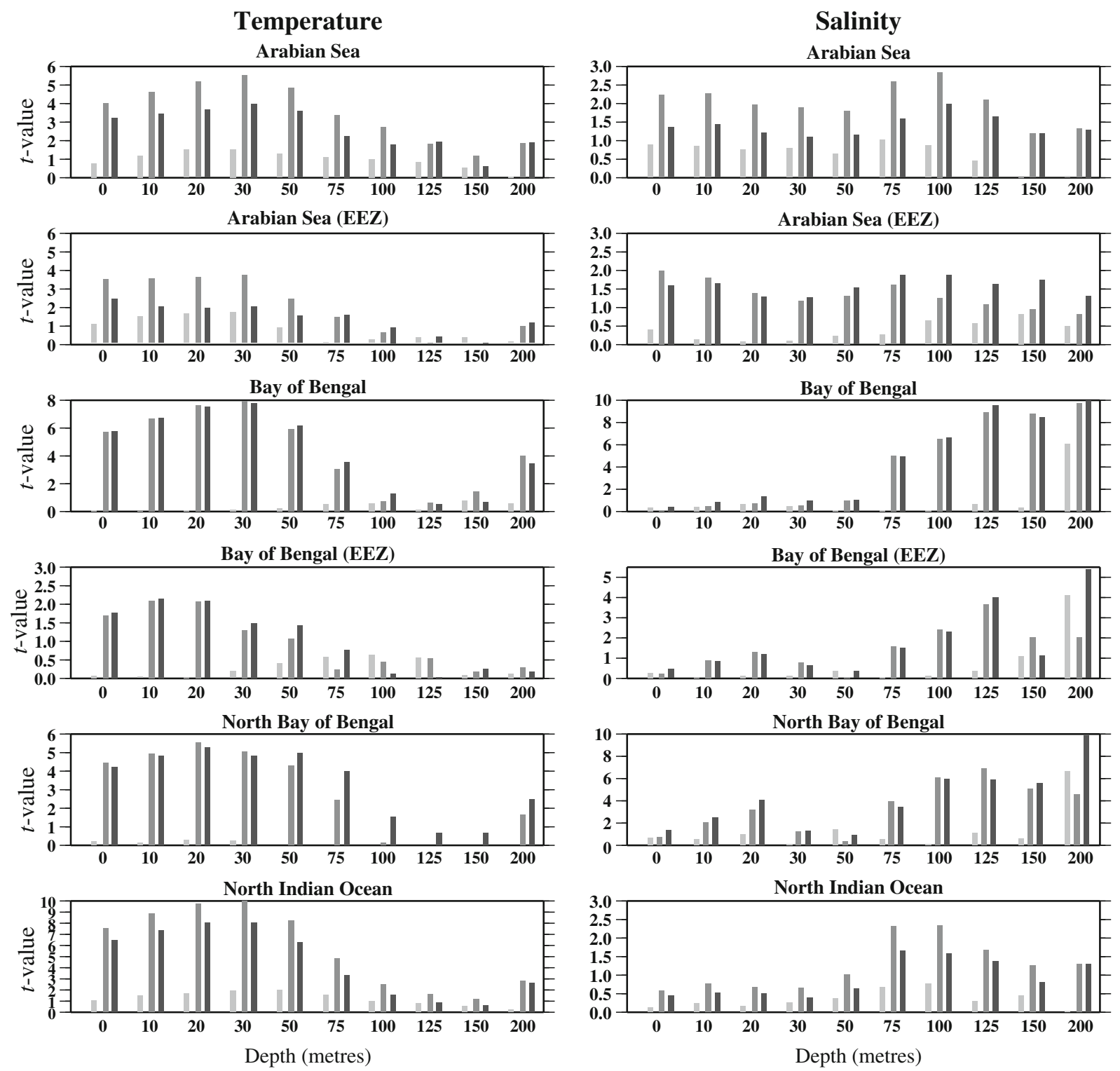

NIOA vs MEAN

WOA vs MEAN

NIOA vs WOA

Figure 15. Significance level of temperature (left) and salinity (right) based on Welch's $t$-test between NIOA and observed mean, WOA09 and observed mean, and NIOA and WOA09.

for the given decade were used to obtain the observed field for each month, resulting in a monthly climatology for each decade. The five monthly climatologies were then averaged to obtain a monthly climatology, which was filtered and smoothed (Tukey 1974; Rabiner et al 1975; Shuman 1957) (see Appendix B) to obtain the final monthly climatology. This method was used in WOA09 to give more weight to data from earlier decades and to avoid the disproportionate weight assigned to more recent decades because of the increase in the amount of data collected over time.
The NIO, however, is a data-sparse region even when data from all decades are combined (see figures 1 and 3). This sparsity of data implies that it is not possible to obtain stable averages if the already sparse data are divided into decadal blocks. Hence, we preferred the WOA05 method for deriving the NIOA climatology. Nevertheless, to check the effect of the WOA09 method, we derived a climatology using this approach too. We divided the data into four decadal blocks (until 1980, 19811990, 1991-2000, 2001-2010). Plots of surface temperature and salinity fields derived using the WOA05 and WOA09 (NIOAW09) methods are shown in 

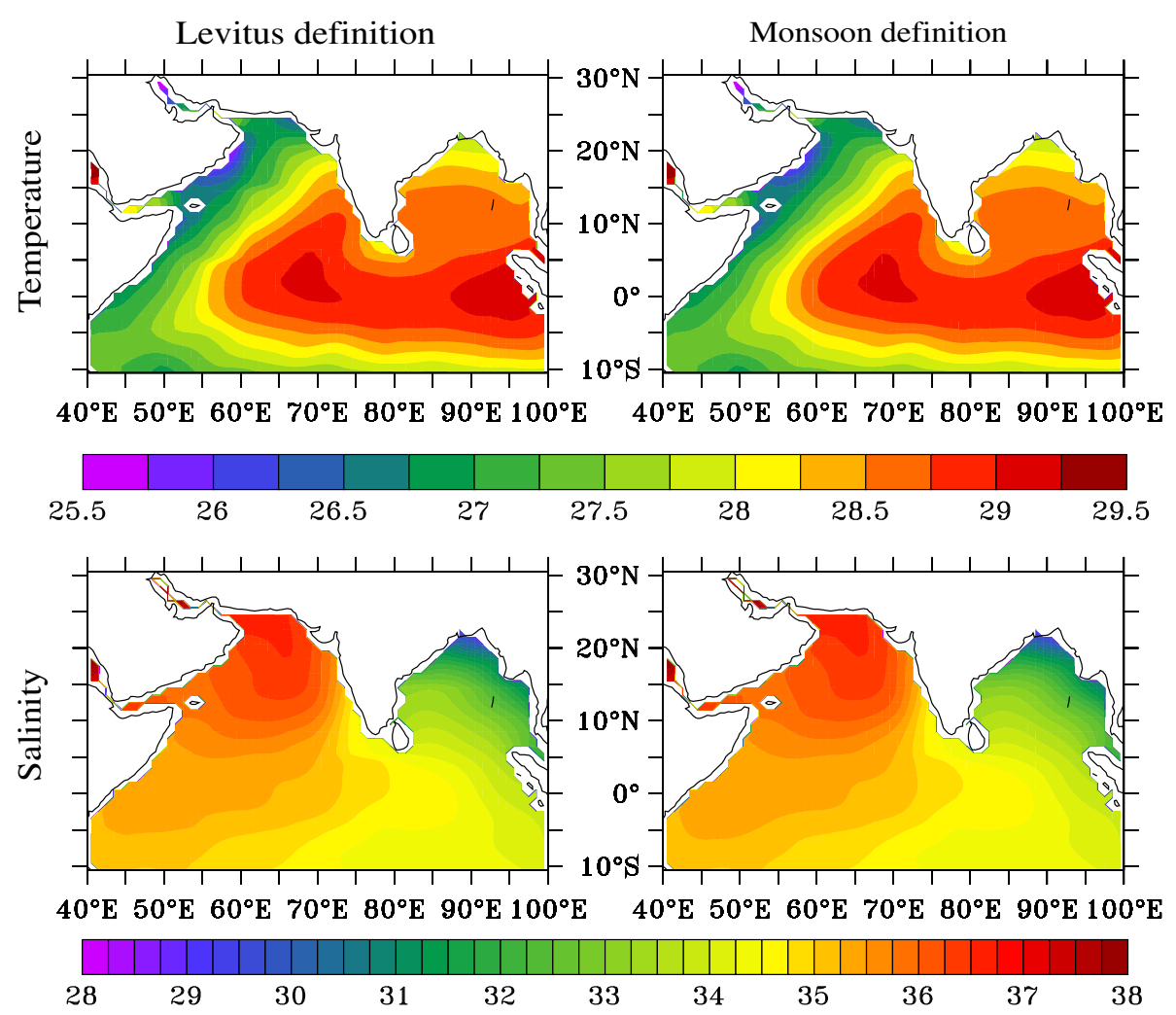

Figure 16. Comparison of surface temperature (top panel) and salinity (bottom panel) between the annual climatology of NIOA (left), in which seasons were defined as given in section 3.2.2, and an annual climatology derived using the monsoonal definition of seasons (right).

figures 18 and 19. The climatologies derived using the WOA05 and WOA09 methods look similar, except in the northern Bay of Bengal, where each decadal climatology was created using very few profiles. For example, during December, the northern Bay of Bengal was data-void until 1980 (figure 20). The primary criterion for this decadal division used in WOA09 is that each decade should uniformly influence the final climatology, which is not possible in the NIO. Hence, we preferred the WOA05 method for deriving the NIOA.

\subsubsection{Gaussian weighted mean}

One criticism of the Levitus climatologies has been the simplicity of the method. The objective analysis procedure used in preparing the Levitus climatologies involves simple averaging, with an inverse-distance-squared weighting to limit the distance to which an observation influences the climatology. In time too, the Levitus procedure uses simple, but iterative, averaging. A consequence of this time averaging is that an observation on, say, 30 April has an influence on the April climatology that is much greater than an observation a day later, on 1 May. The reason for this drastic difference is that the April observation contributes directly to the average for the cell, but the influence of the May observation has to be accounted for through the first-guess field or the analysed seasonal climatology. (A similar problem exists for the seasonal climatology too, with a day's separation in observations leading them to be assigned to different seasons.) Likewise, in space, the Levitus method assigns equal weights to all points within a $1^{\circ} \times 1^{\circ}$ grid cell, irrespective of their distance from the centre of the cell.

A more sophisticated approach is to allow each observation, irrespective of its location or time of sampling, to have an influence on all grid cells at all times. Such a method, in which a Gaussian weighted mean serves as the interpolating function, was used by Kessler and McCreary (1993) in their study of the subthermocline equatorial Pacific. We adapted their method to the creation of a monthly climatology for the NIO. Let

$$
Q^{i, j}=\frac{\sum_{m=1}^{n} W_{m} Q_{m}}{\sum_{m=1}^{n} W_{m}},
$$

where $i$ and $j$ represent the coordinates of a cell in the zonal and meridional directions, respectively, 


\section{Seasonal climatology for monsoon definition of seasons}

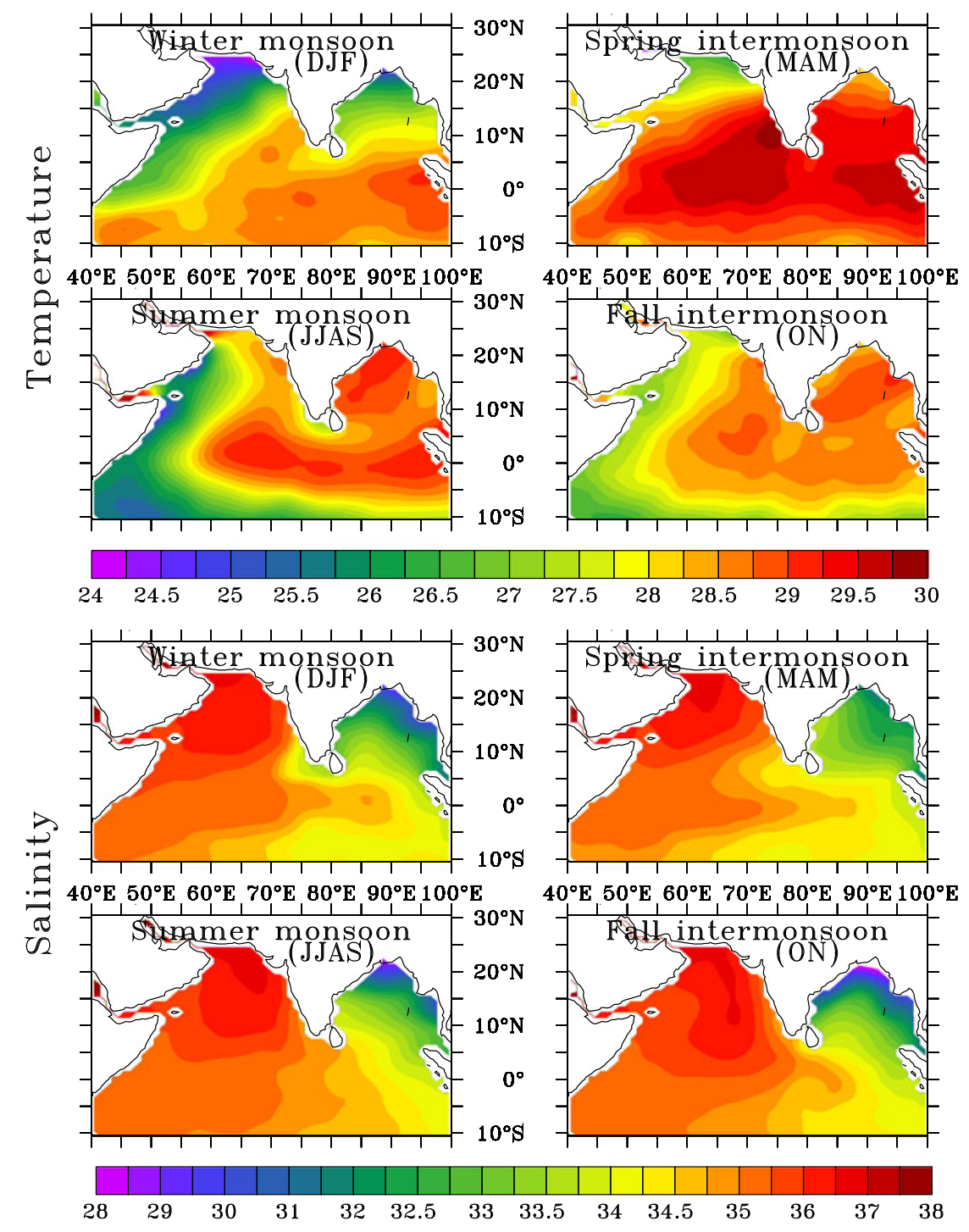

Figure 17. Surface temperature and salinity of seasonal climatology derived using the new monsoonal definition of seasons.

$Q^{i, j}$ is the gridded value of the variable (temperature $T$ or salinity $S$ ) for cell $(i, j), n$ is the number of grid cells with a non-zero $Q$ within a distance $R$ of cell $(i, j), Q_{m}$ is the $m$ th value of variable $Q$ within this influence radius, and $W_{m}$ is the weight assigned to the value $Q_{m}$. The weight $W_{m}$ for an observation at $\left(x_{m}, y_{m}, t_{m}\right)$ is given by:

$$
\begin{gathered}
W_{m}\left(x_{m}, y_{m}, t_{m}\right)=\exp \left\{-\left[\left(\frac{x_{m}-x_{i}}{X}\right)^{2}\right.\right. \\
\left.\left.+\left(\frac{y_{m}-y_{j}}{Y}\right)^{2}+\left(\frac{t_{m}-t}{\tau}\right)^{2}\right]\right\},
\end{gathered}
$$

where $\left(x_{i}, y_{j}, t\right)$ represents the value of $Q$ at the location $\left(x_{i}, y_{j}\right)$ and time $t$, and $X, Y$, and $\tau$ represent the zonal, meridional and temporal mapping scales. Note the similarity to equation (1) in the WOA05 method. One difference, however, is that in this method, the $m$ th observation does not represent a cell average. Another difference is in the time interpolation, which is treated here in a manner similar to spatial interpolation. We chose $X=2^{\circ}, Y=2^{\circ}$, and $\tau=21$ days. For these choices, the weight drops to 0.0183 within a $2^{\circ}$ radius or within 42 days of the middle of each month. In principle, all data points influence the value in each cell, but in practice, the Gaussian function implies a rapid decrease in the weight with distance or time. We truncated the weight to zero when it fell below $e^{-5}$.

This method is mathematically superior to that used in creating the Levitus climatologies, but, as 
NIOA
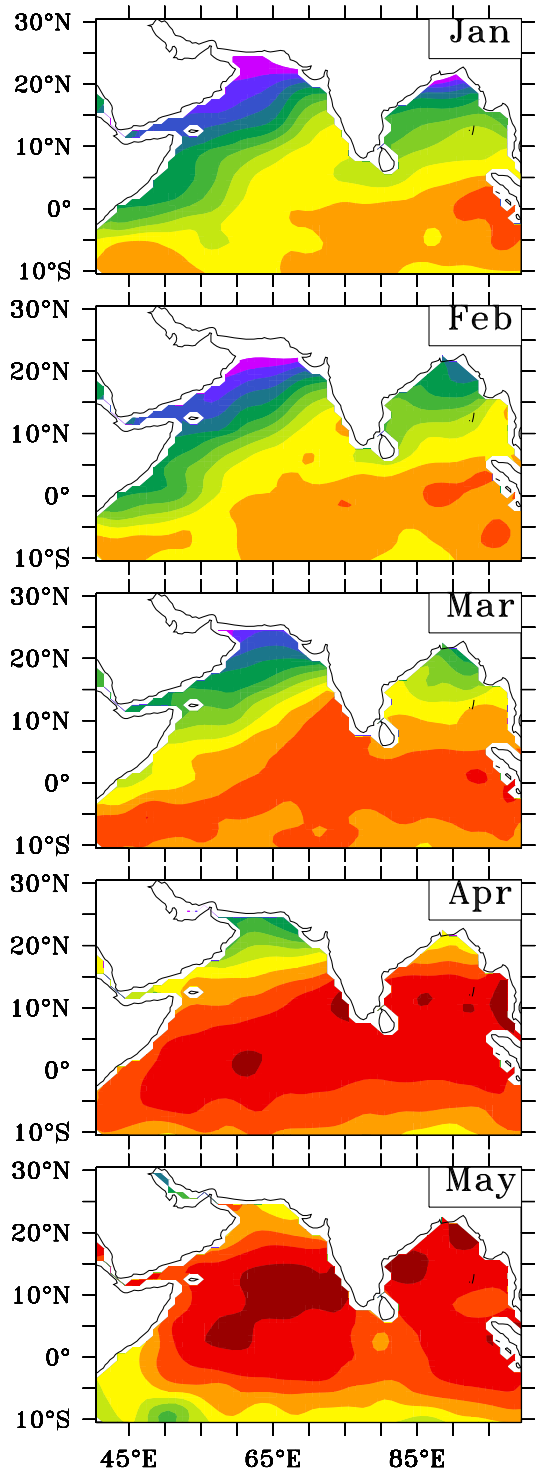

NIOAW09
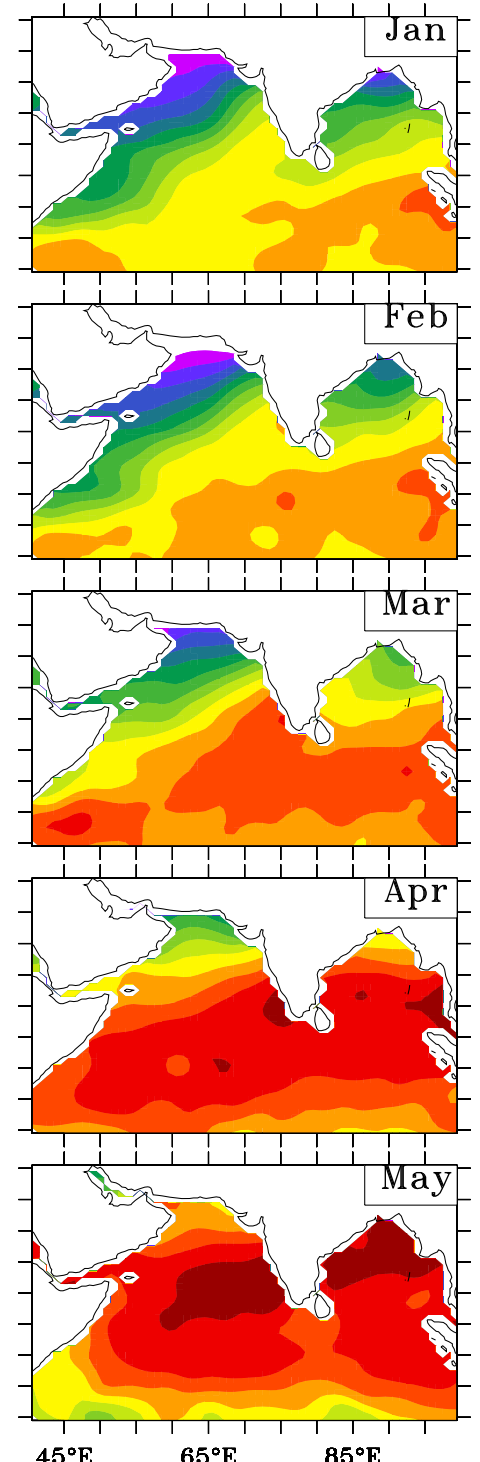

KESSLER
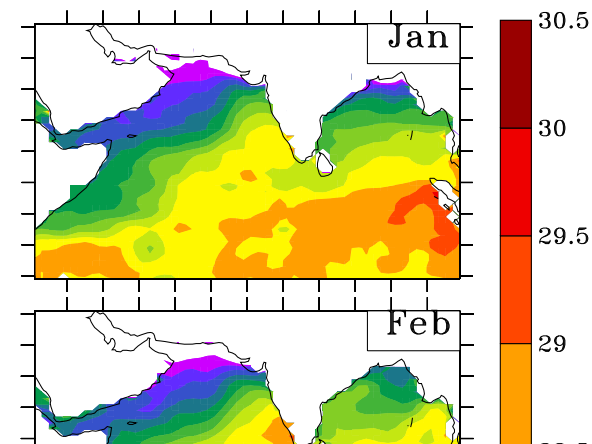

28.5
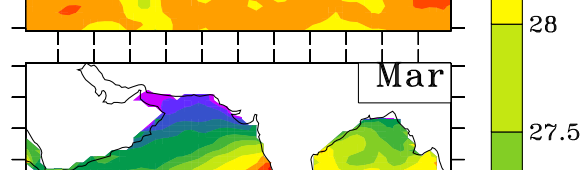

27.5

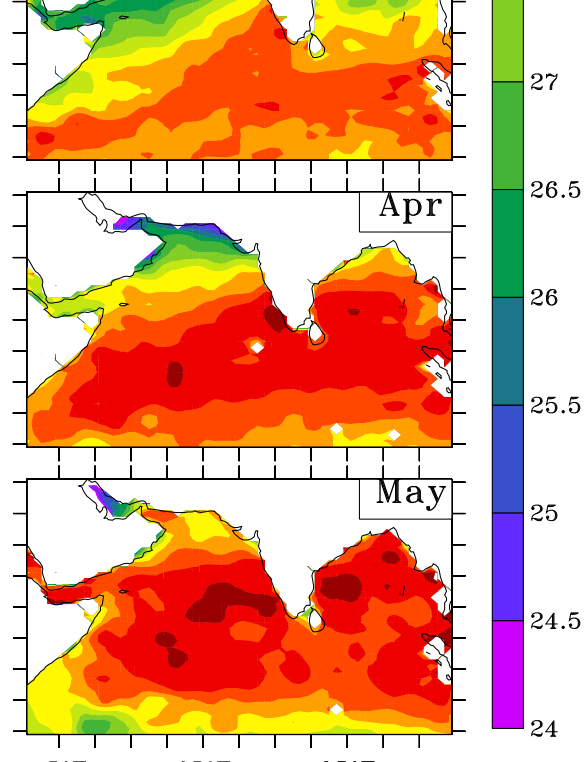

$45^{\circ} \mathrm{E} \quad 65^{\circ} \mathrm{E} \quad 85^{\circ} \mathrm{E}$

Figure 18. Comparison of surface temperature between NIOA (left), in which we followed the method used in WOA05 and climatologies derived using the WOA09 method (middle) and the method of Kessler and McCreary (1993) (right).

seen in the comparison in figure 18, it does not work as well. This method could produce almost all major features in the NIO, but the uneven distribution of data in space and time produces many unrealistic patches. Changing the values used for $X, Y$ and $\tau$ did not change the result.

Note that the change in method of interpolation from one version of the Levitus climatology to the next also resulted in similar problems in datasparse regions (figure 2): regions with a more even distribution of data are less sensitive to a change in interpolation method because the local average is more stable. Thus, the Levitus method, in spite of its simplicity, works better in the data-sparse NIO because the zonal averaging used to produce the first-guess field makes up for missing data.

\subsection{Concluding remarks}

The improvement in the climatology answers some questions and probably raises some new questions. One problem faced by numerical modellers has been the inability of models to simulate the poleward extent of the low-salinity water during winter along the Indian west coast (Han and McCreary 2001; Durand et al 2007; Kurian and Vinayachandran 2007). The difficulty in getting the models to match the poleward penetration seen in the Levitus climatologies (figure 8) led to some modellers arguing in favour of a substantial flow of the low-salinity water of Bay-of-Bengal origin through the shallow Adam's-Bridge region in the gap between India and Sri Lanka (Han and McCreary 2001), but an 
NIOA

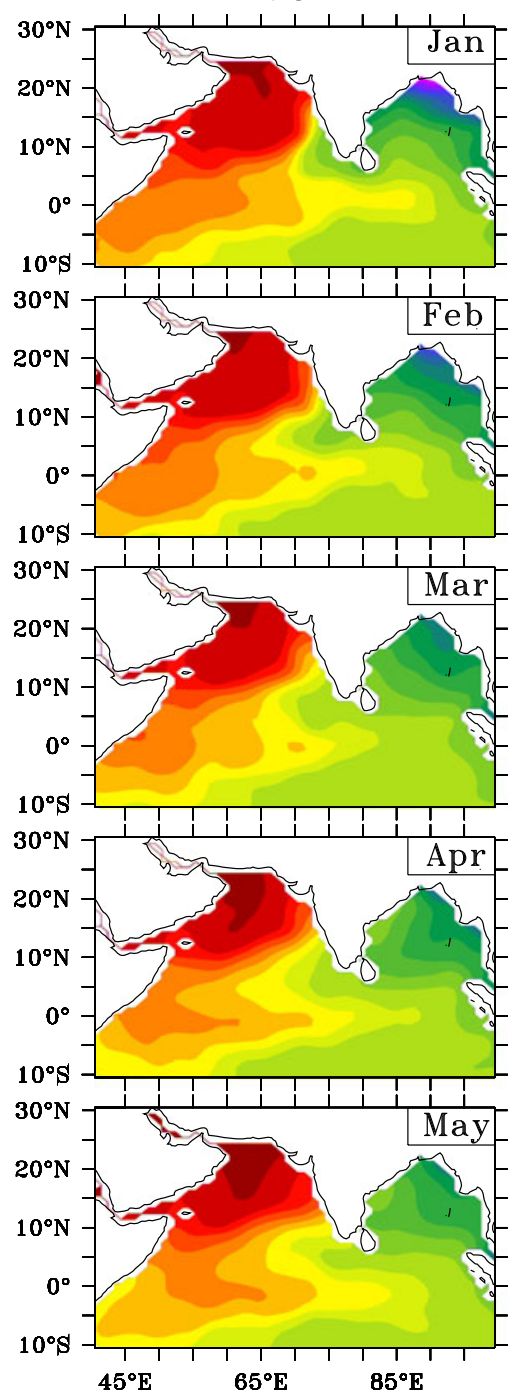

NIOAW09
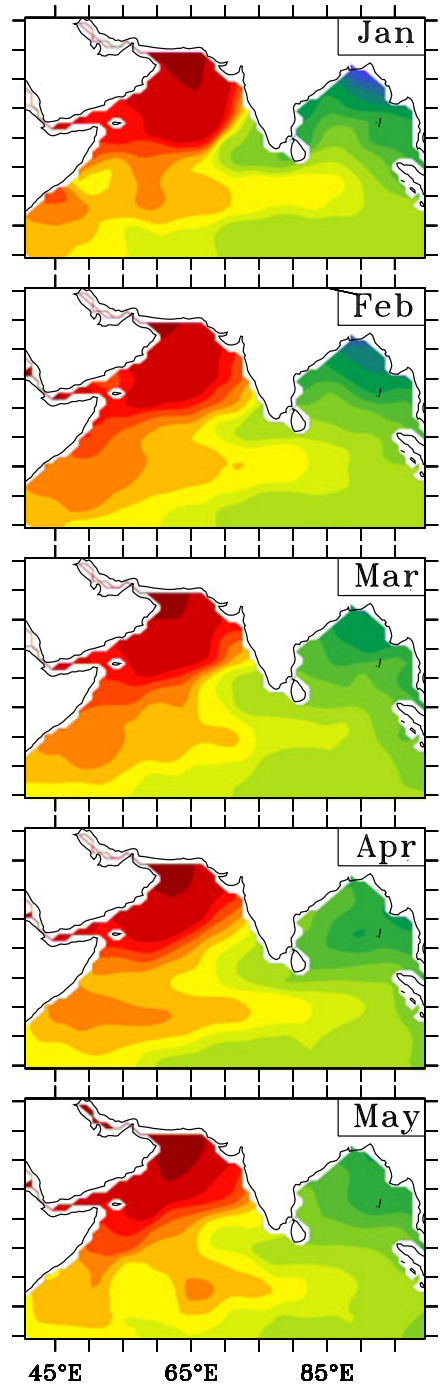

KESSLER

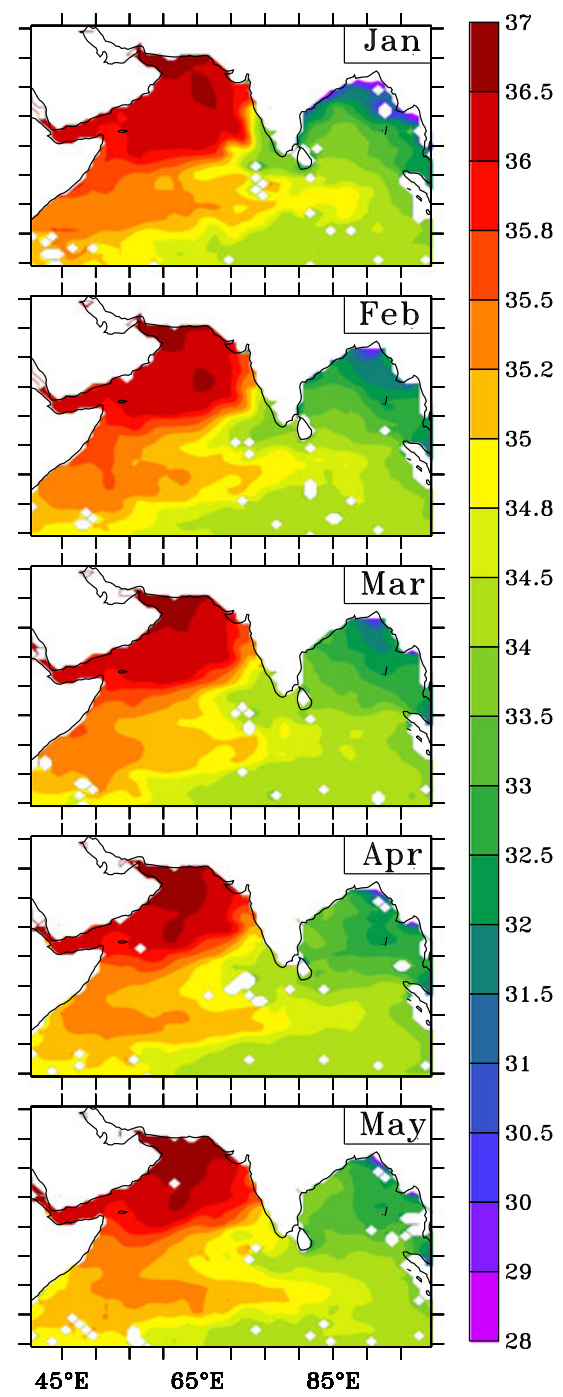

Figure 19. Comparison of surface salinity between NIOA (left), in which we followed the method used in WOA05 and climatologies derived using the WOA09 method (middle) and the method of Kessler and McCreary (1993) (right).

examination of the bathymetry in the region rules out a large transport through this gap (Durand et al 2007). Recent modelling results suggest that a possible reason for this model deficiency is the coarse resolution of earlier studies; the EICC is too weak in a model with a horizontal resolution of $0.5^{\circ}$ to be able to transport the low-salinity waters to the west coast before the current reverses direction (Durand et al 2011). In the NIOA, a considerable amount of data was added in the Indian EEZ in the eastern Arabian Sea (figure 3), and the NIOA salinity field shows that the low-salinity water spreads more westward off southwest India than poleward along the coast (figure 8), as seen in these numerical models. The reason for this westward spread is the existence of the Lakshadweep High, an anticyclonic circulation in the SEAS (McCreary et al 1993; Bruce et al 1994; Shankar and Shetye
1997) in which the low-salinity water gets trapped (Shenoi et al 1999; Kurian and Vinayachandran 2007).

Note, however, that most of these models were forced either by climatological winds or by satellitederived wind-forcing products, all of which tend to be biased towards the recent decades. The salinity data in the NODC database, and therefore in the Levitus climatologies, date back to the IIOE period in the $1960 \mathrm{~s}$, while the additional Indian data in the NIOA are biased more towards the recent decades (figure 1). Therefore, a question that arises is the following: is the difference between the salinity fields in WOA09 and NIOA due to decadal variability? The eastern Arabian Sea is perhaps the only part of the Indian EEZ in which the data distribution is good enough in the NODC database to produce a stable average: there 


\section{Number of profiles for December}

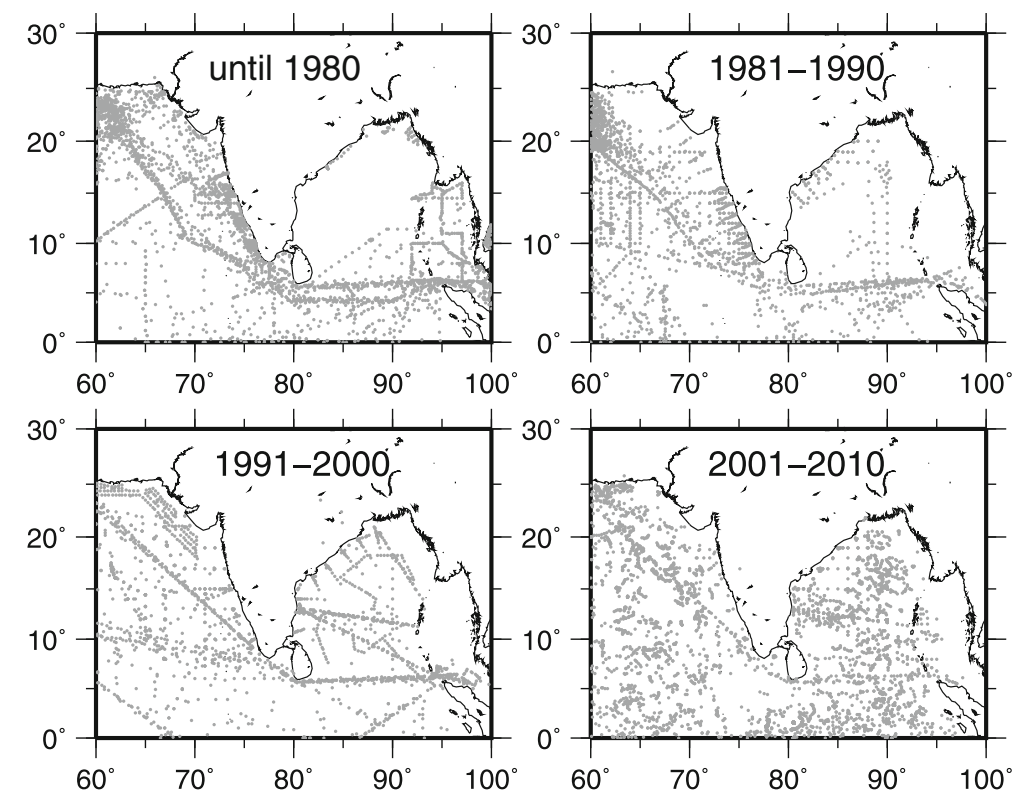

Figure 20. Spatial distribution of the available profiles (for both temperature or salinity) for each decade during December.

is little change in the salinity of this region across the different Levitus climatologies (figure 2). An answer to this question may therefore be sought by preparing separate monthly climatologies for the different decades. Figure 21 shows the climatology for the months of December, January and February for each four decades separately as defined in section 5.2.1. For example, there is considerable variation in the salinity contours from one decade to another in the SEAS, suggesting that decadal variability is important. One reason for this decadal variability could be variability in the monsoon rainfall (Gopalakrishna et al 2005) over the Indian subcontinent, particularly in the Bay of Bengal, but the uneven distribution of data in time and space implies that the averages for each decade are not equally reliable.

The Levitus atlases and NIOA yield a statistical summary of the profile data on a uniform grid. They do not include dynamical information, unlike the FRAM (Fine-Resolution Antarctic Modelling) Atlas (Webb et al 1991), in which the hydrographic profiles are assimilated into a nonlinear dynamical model to produce a series of snapshots that are not only close to the observations, but also dynamically consistent (see John Woods' preface to Webb et al 1991). In the NIO, and in the Bay of Bengal in particular, however, it is not clear if such an approach will make up for the sparsity of data. One important forcing variable that is poorly documented is river discharge (Shankar et al 2004; Yaremchuk et al 2005), which has a major impact on the salinity field in the northern bay and in regions such as the SEAS to which the low-salinity water is advected by the currents. Since the salinity field, in turn, plays a major role in determining the SST in the northern bay (Shenoi et al 2002), it is unclear if such an atlas based on a dataassimilating modelling system is feasible today for the NIOA.

What is possible, however, is to change the method used for vertical interpolation. Instead of averaging on depth surfaces, it is possible to average on surfaces of potential density (isopycnals) because mixing and flows in the deeper ocean tend to occur along isopycnals rather than across them. Such an approach, as used by Lozier et al (1995), would eliminate the artificial mixing of water masses induced by the Levitus averaging procedure. We have, however, followed the Levitus method because an important objective of this work is to enable NIOA to be merged seamlessly with WOA09.

In summary, we have added data from Indian sources to the databases of NODC and JODC and prepared a new atlas of the NIO. We used several methods to prepare the NIOA climatology, but the one that worked best was the one used to prepare WOA05. The addition of data improves the climatology considerably in the Indian EEZ, the differences between the NIOA and WOA09 being most significant in the Bay of Bengal, where the patchiness of the Levitus climatologies, an artifact of the sparsity of data, was eliminated in NIOA. The significance of the new climatology is that it presents a more stable climatological 


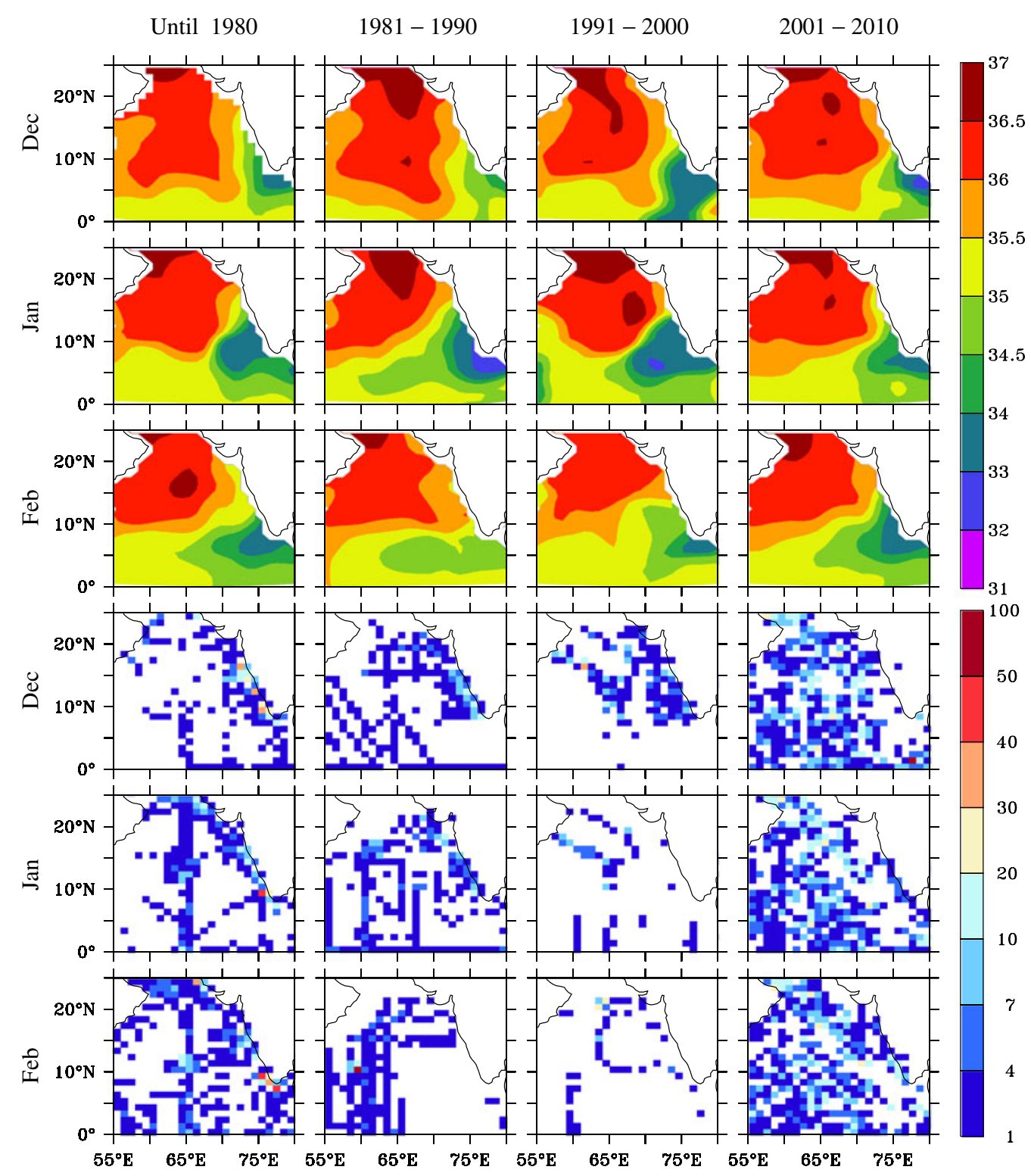

Figure 21. Surface salinity (top three rows) in the eastern Arabian Sea (off the Indian west coast) during DecemberFebruary for four different decades. These climatologies were prepared using the WOA09 method, but were filtered and smoothed without averaging over the decades. The bottom three rows show the number of salinity profiles available in this region in each of these four decades.

value for the temperature and salinity fields in the Indian EEZ.

\section{Acknowledgements}

The authors thank Dr Timothy Boyer for several helpful discussions on the methodology used in the Levitus climatologies. D Shankar thanks Dr Clement de Boyer Montegut for pointing out the need to explain why the vertical averaging is done on level surfaces. SGI Altix situated in NIO was used for all numerical computations. This work was supported by CSIR through its funding of NIO's SIP; additional funding was obtained from INCOIS (Ministry of Earth Sciences) under their INDOMOD programme. Ferret and Generic Mapping Tool were extensively used for analysis and plotting the figures. The critical comments from two anonymous reviewers helped considerably in improving this manuscript. Three-daymean TMI SST has been obtained from SSMI (http://www.ssmi.com/tmi/tmi_browse.html). Finally, the authors thank all those who were responsible for collecting the data that went into preparing this climatology. This is NIO contribution 5097 and INCOIS contribution 93. 


\section{Appendix A}

\section{Quality-control procedure}

The quality-control procedure follows the procedure used in preparing the World Ocean Atlas (Boyer et al 2002; Stephens et al 2002; Antonov et al 2006; Locarnini et al 2006). A brief description of the procedure is given below. Profiles that did not pass a check were discarded; the number of profiles discarded after each check is listed in table 4.

\section{A.1 Duplicate profile check}

Since we have obtained data from different sources, it is possible for the same profile to exist in more than one dataset, or for it to be duplicated within the same source. Hence, the first step of quality control is to check for and discard the duplicate profiles. The NODC dataset was used as the reference dataset. A duplicate profile is one that contains identical or near-identical information (including position, date, time and the data values) as another profile.

\section{A.2 Duplicate depth check}

This check is carried out to prevent any duplication of a depth in a single profile. This situation may arise owing to human error or to missing header information for a profile (in which case, two successive profiles in a file may appear as one profile).

\section{A.3 Correction in XBT drop rate}

$\mathrm{XBT}$ probes measure only time and temperature. Depth is estimated using a vendor-specified timelapse equation, but the probe actually falls faster than estimated by the vendor-specified drop rate. Therefore, the XBT depths have to be corrected

Table 4. Number of profiles retained after each quality-control procedure.

\begin{tabular}{|c|c|c|c|c|c|c|}
\hline \multirow[b]{2}{*}{ Source } & \multicolumn{2}{|c|}{ Before check } & \multicolumn{2}{|c|}{ After check } & \multicolumn{2}{|c|}{ No. of profiles discarded } \\
\hline & Temperature & Salinity & Temperature & Salinity & Temperature & Salinity \\
\hline \multicolumn{7}{|c|}{ Range check } \\
\hline NODC & 417276 & 139455 & 389392 & 121875 & 27884 & 17580 \\
\hline INODC & 18837 & 13159 & 18803 & 13120 & 34 & 39 \\
\hline JODC & 4383 & 606 & 4273 & 605 & 110 & 01 \\
\hline ARGO & 75843 & 74647 & 75554 & 73623 & 289 & 1024 \\
\hline CMFRI & 1432 & 1390 & 1421 & 1377 & 11 & 13 \\
\hline CMLRE & 2264 & 2262 & 2263 & 2242 & 01 & 20 \\
\hline \multicolumn{7}{|c|}{ Inversion and gradient check: I } \\
\hline NODC & 389392 & 121875 & 389141 & 121875 & 251 & 00 \\
\hline INODC & 18803 & 13120 & 18803 & 13120 & 00 & 00 \\
\hline JODC & 4273 & 605 & 4273 & 605 & 00 & 00 \\
\hline ARGO & 75554 & 73623 & 75553 & 73623 & 01 & 00 \\
\hline CMFRI & 1421 & 1377 & 1421 & 1377 & 00 & 00 \\
\hline CMLRE & 2263 & 2242 & 2263 & 2242 & 00 & 00 \\
\hline \multicolumn{7}{|c|}{ Inversion and gradient check: II } \\
\hline NODC & 389141 & 121875 & 388139 & 121302 & 1002 & 573 \\
\hline INODC & 18803 & 13120 & 18797 & 13117 & 04 & 03 \\
\hline JODC & 4273 & 605 & 4273 & 601 & 00 & 04 \\
\hline ARGO & 75553 & 73623 & 74614 & 73323 & 939 & 09 \\
\hline CMFRI & 1421 & 1377 & 1421 & 1373 & 01 & 04 \\
\hline CMLRE & 2263 & 2242 & 2262 & 2241 & 01 & 01 \\
\hline \multicolumn{7}{|c|}{ Time series, duplicate and statistical check } \\
\hline NODC & 388139 & 121302 & 356759 & 108232 & 9855 & 5457 \\
\hline INODC & 18797 & 13117 & 15166 & 9789 & 3631 & 3328 \\
\hline JODC & 4273 & 601 & 2965 & 342 & 1308 & 259 \\
\hline ARGO & 74614 & 73323 & 39070 & 37730 & 35544 & 35593 \\
\hline CMFRI & 1421 & 1373 & 1200 & 1171 & 221 & 202 \\
\hline CMLRE & 2262 & 2241 & 1927 & 1898 & 355 & 343 \\
\hline
\end{tabular}


for this error, and the correction is made using a drop-rate equation due to Hanawa et al (1994):

$$
\begin{aligned}
z_{c}= & 1.0417 z_{0}-75.906 \\
& \times\left[1-\left(102.063 \times 10^{-4} z_{0}\right)^{(1 / 2)}\right],
\end{aligned}
$$

where $z_{0}$ is the observed depth and $z_{c}$ is the corrected depth.

The XBT data in WOA were corrected using the above equation (Timothy Boyer, personal communication, 2010). The Indian XBT data used in the present study consist of repeat transects in the Indian Ocean. The XBT data were processed and quality-controlled following Bailey et al (1994). XBT profiles pertaining to individual cruises were plotted and physically verified for probe-to-probe consistency, identifying genuine temperature inversions and sharp spikes. These profiles were then compared with the corresponding WOA05 (Locarnini et al 2006) climatological profile of that region and also with the climatology developed using the Indian XBT data of that transect. The SST values of the individual XBT profiles were replaced by the temperature at $4.5 \mathrm{~m}$ depth in order to compensate for the thermistor response time. Suspect XBT profiles, amounting to about $10 \%$, were removed from the main dataset.

Gouretski and Koltermann (2007) have shown that there is year- and depth-varying warm temperature bias in the XBT instrument, and Wijffels et al (2008) have shown that the temperature bias is mainly due to small variations in the drop-rate equation. Levitus et al (2009) modified the Gouretski and Koltermann (2007) biases and extended the bias calculation through the year 2008. For the years $2000-2008$, the mean bias in the upper 100 $\mathrm{m}$ is $0.13^{\circ} \mathrm{C} \pm 0.06^{\circ} \mathrm{C}$ Levitus et al (2009). Nevertheless, in order to quantify the possible error due to the XBT bias problem, a large bias $\left(0.2^{\circ} \mathrm{C}\right)$ was assumed to be present in all XBT deployments. Accordingly, the depth of the $25.0^{\circ} \mathrm{C}$ (D25) and $25.2^{\circ} \mathrm{C}$ (D25.2) isotherms were calculated, and the differences were estimated. Over most months and years, the typical depth error due to the XBT bias does not exceed $1.5 \mathrm{~m}$. On very few instances did the error exceed $3 \mathrm{~m}$. These errors remain much smaller than the typical range of D25 variations. As shown by Gouretski and Koltermann (2007), this bias is important for estimating the heat content of the water column; it is not relevant, however, for preparation of a climatology.

\section{A.4 Conversion from pressure to depth for Argo profiles}

A typical Argo profile gives position, pressure, temperature and salinity. Depth can be derived from pressure and latitude. In shallow water, pressure in decibars is numerically equal to the depth in metres, but there is a difference between this pressure and depth in the deep ocean. Furthermore, the acceleration due to gravity is less at the equator than at the poles; hence, we need to consider latitude as well when converting pressure to depth. The equation (Saunders and Fofonoff 1976; Fofonoff and Milland 1983): depth in metres, is given by:

$$
z=\frac{c_{1} p+c_{2} p^{2}+c_{3} p^{3}+c_{4} p^{4}}{g(\phi)+\frac{1}{2} \gamma^{\prime} p},
$$

where $p$ is the pressure in decibars, $g(\phi)$ is the acceleration due to gravity $\left(\mathrm{m} \mathrm{s}^{-2}\right)$, and $\gamma^{\prime}=$ $2.184 \times 10^{-6}\left(\mathrm{~m} \mathrm{~s}^{-2} /\right.$ decibar $)$, with

$$
\begin{aligned}
& c_{1}=9.72659, c_{2}=-2.2512 \times 10^{-5}, \\
& c_{3}=2.279 \times 10^{-10}, c_{4}=-1.82 \times 10^{-15}
\end{aligned}
$$

and

$$
\begin{aligned}
g(\phi)= & 9.780318 \times\left[1.0+\left(5.2788 \times 10^{-3}\right.\right. \\
& \left.\left.+2.36 \times 10^{-5} \sin ^{2} \phi\right) \sin ^{2} \phi\right],
\end{aligned}
$$

where $\phi$ is the latitude.

\section{A.5 Range check}

This check is carried out to ensure that data lie within a prescribed range. As can be seen from the permissible range for temperature and salinity (table 5), this range check discards only those data that are grossly in error. A larger range for temperature had to be prescribed for the Red Sea and Persian Gulf because the maximum temperature in these two sub-basins is higher than in the rest of the Indian Ocean (table 6). If a profile contained three or more erroneous observations or data values, then the entire profile was discarded.

\section{A.6 Inversion and gradient checks}

Though temperature inversions and high temperature gradients are observed in some regions in some seasons, abrupt temperature inversions or unusually large temperature gradients, which can be seen in some profiles, are obviously due to data errors. To eliminate such errors, we prescribed the acceptable range of temperature inversion and gradient. The gradient is defined as:

$$
T_{z}=\frac{T_{2}-T_{1}}{Z_{2}-Z_{1}}
$$

where $T_{2}$ and $T_{1}$ are the temperatures at depths $Z_{2}$ and $Z_{1}$, respectively, with level 2 being deeper than 
Table 5. Prescribed bounds for temperature and salinity used in the range check.

\begin{tabular}{|c|c|c|c|c|c|c|}
\hline \multirow[b]{2}{*}{ Latitude } & \multirow[b]{2}{*}{ Longitude } & \multirow[b]{2}{*}{ Depth } & \multicolumn{2}{|c|}{ Temperature } & \multicolumn{2}{|c|}{ Salinity } \\
\hline & & & Maximum & Minimum & Maximum & Minimum \\
\hline \multirow[t]{5}{*}{$30^{\circ} \mathrm{S}-5^{\circ} \mathrm{N}$} & $30^{\circ}-120^{\circ} \mathrm{E}$ & $\leq 100$ & 31.8 & 10 & 38 & 26 \\
\hline & & $125-200$ & 30 & 5 & & \\
\hline & & $300-500$ & 30 & 2 & & \\
\hline & & $600-1000$ & 25 & 2 & & \\
\hline & & $>1000$ & 25 & - & & \\
\hline \multirow[t]{3}{*}{$5^{\circ}-30^{\circ} \mathrm{N}$} & $30^{\circ}-50^{\circ} \mathrm{E}$ & do & do & do & 25 & 43 \\
\hline & $50^{\circ}-80^{\circ} \mathrm{E}$ & do & do & do & 25 & 38 \\
\hline & $80^{\circ}-120^{\circ} \mathrm{E}$ & do & do & do & 14 & 36 \\
\hline $30^{\circ}-40^{\circ} \mathrm{N}$ & $30^{\circ}-120^{\circ} \mathrm{E}$ & do & do & do & 20 & 38 \\
\hline
\end{tabular}

Table 6. Prescribed temperature range for Red Sea and Persian Gulf.

\begin{tabular}{lcc} 
& \multicolumn{2}{c}{ Temperature } \\
\cline { 2 - 3 } Depth & Maximum & Minimum \\
\hline$\leq 100$ & 40 & 10 \\
$125-200$ & 30 & 5 \\
$300-500$ & 30 & 2 \\
$600-1000$ & 25 & 2 \\
$>1000$ & 25 & - \\
\hline
\end{tabular}

level 1. Therefore, a negative gradient represents an inversion.

The acceptable values of temperature gradient and inversions differ between the subsurface ocean and deep ocean, we have to prescribe different limits for them (table 7). Furthermore, the temperature gradient in the Somali region is higher in the months preceding the onset of the summer monsoon; hence, a different range had to be prescribed for this region. This check was carried out twice, once after the range check and again after the vertical interpolation.

A similar check was not performed for salinity because inversions in salinity are common and cannot be subject to the same kind of quality checks.

\section{A.7 Static-stability check}

To check the stability of the water column, a local static stability $(E)$ check followed by Lynn and Reid (1968) was applied to each profile containing both temperature and salinity. Stability $E$ is given by:

$$
E=\frac{1}{\rho_{0}} \frac{\delta \rho}{\delta z},
$$

where $\rho_{0}=1.02 \times 10^{3} \mathrm{~kg} \mathrm{~m}^{-3}$.

To calculate the local static stability at level $(k+1)$, the density difference is defined by the deference between in-situ density at level $k$ to the
Table 7. Prescribed temperature inversion and gradient values.

\begin{tabular}{lccc}
\hline Region & Depth & $\begin{array}{c}\text { Maximum } \\
\text { inversion } \\
\text { value }\end{array}$ & $\begin{array}{c}\text { Maximum } \\
\text { gradient } \\
\text { value }\end{array}$ \\
\hline $\begin{array}{l}\text { Indian Ocean } \\
\text { (Except Somali }\end{array}$ & Depth $\leq 200 \mathrm{~m}$ & 0.3 & 1.0 \\
$\quad$ Region) & Depth $>200 \mathrm{~m}$ & 0.3 & 0.7 \\
Somali Region & Depth $\leq 200 \mathrm{~m}$ & 0.3 & 1.0 \\
& Depth $>200 \mathrm{~m}$ & 0.3 & 0.8 \\
\hline
\end{tabular}

density of a parcel at level $(k+1)$ after the parcel is taken adiabatically to the level $k$.

To a depth of $30 \mathrm{~m}$, if the static stability $(E)$ inversions exceed $3 \times 10^{-2} \mathrm{~m}^{-1}$ for an observation in a profile, then that observation (both temperature and salinity) was flagged. Similarly below this depth to $400 \mathrm{~m}$, if inversions exceed $2 \times 10^{-2} \mathrm{~m}^{-1}$ then that observation was flagged. Below 400-1000 $\mathrm{m}$, if the inversions exceed $1 \times 10^{-2} \mathrm{~m}^{-1}$, those observations were flagged and any observation of inversions below $1000 \mathrm{~m}$ depth were flagged and eliminated from the database. Note that we never flagged the whole profile, instead we flagged those observations, which were failed in static stability criterion.

\section{A.8 Standard-deviation check}

This check followed the procedure described in WOA05, except that the Persian Gulf and Red Sea were accounted for separately because of the high temperature and salinity gradients between these two sub-basins and the adjacent part of the Arabian Sea. The standard deviation is biased by this contrast if the $5^{\circ}$ box used for the standard deviation computation covers part of either sub-basin or a part of the Arabian Sea. Hence, we carried out this check separately for the Persian Gulf and the Red Sea. 


\section{A.9 Time-series and UOR profile management}

Time-series observations, whether using ship-based instrumentation or moorings (UOR), present a problem because of the large number of profiles in a small geographic area. The averages are biased if each profile in a time series is considered independent of the others and all are given equal weight. Hence, time-series databased on ship-based instrument were first averaged over a day, i.e., all the observations over a day yielded just a single profile. Similarly, for UOR (moored buoys), data were averaged over a month, i.e., all the observations over a month yielded just a single profile.

\section{Appendix B}

\section{Filtering and smoothing}

The analysed climatologies were filtered and smoothed to reduce the noise in the data; the result of the filtering and smoothing operations was the final climatology.

Suppose $Y_{\mathrm{a}}^{i, j}$ is the analysed field for cell $(i, j)$. It was first filtered using a five-point median filter; the other four cells used in this operation were the adjacent cells to the east, west, north and south of this cell. The median of these five values was used as the median-filtered value, $Y^{i, j}$.

$Y^{i, j}$ was then filtered with a three-point Hanning window along the latitude belt.

$$
Y_{H}^{i, j}=0.5 Y^{i, j}+0.25\left(Y^{i-1, j}+Y^{i+1, j}\right) .
$$

This Hanning-filtered value was used to estimate the noise.

$$
N^{i, j}=Y_{\mathrm{a}}^{i, j}-Y_{H}^{i, j} .
$$

The resulting noise field was similarly filtered with the five-point median filter and the three-point Hanning window (along a latitude belt) to smooth the noise. This filtered noise field $N_{H}^{i, j}$ was added to $Y_{H}^{i, j}$ to obtain the filtered field $F^{i, j}$ :

$$
F^{i, j}=Y_{H}^{i, j}+N_{H}^{i, j} .
$$

The filtered field $F^{i, j}$ was smoothed with a fivepoint smoothing operator (Shuman 1957). The smoothing operation for cell $(i, j)$ is:

$$
\begin{aligned}
F^{i, j}= & \mu F^{i, j}+0.25(1-\mu) \\
& \times\left(F^{i-1, j}+F^{i+1, j}+F^{i, j-1}+F^{i, j+1}\right),
\end{aligned}
$$

or

$$
\begin{gathered}
F^{i, j}=F^{i, j}+0.25 \nu\left(F^{i-1, j}+F^{i+1, j}+F^{i, j-1}\right. \\
\left.+F^{i, j+1}-4 F^{i, j}\right),
\end{gathered}
$$

where $\nu=1-\mu$. In this paper, we have used $\nu=0.5$.

\section{References}

Antonov J I, Locarnini R A, Boyer T P, Mishonov A V and Garcia H E 2006 World Ocean Atlas 2005, Volume 2: Salinity. NOAA Atlas NESDIS 62, NOAA, U.S. Government Printing Office, Washington D.C.

Antonov J I, Seidov D, Boyer T P, Locarnini R A, Mishonov A V and Garcia H E 2010 World Ocean Atlas 2009, Volume 2: Salinity. NOAA Atlas NESDIS 69, NOAA, U.S. Government Printing Office, Washington D.C.

Bailey R, Gronell A, Phillips H, Meyers G and Tanner E 1994 CSIRO Cookbook for Quality Control of Expendable Bathythermograph (XBT) Data; CSIRO Marine Laboratories Report No. 220.

Barnes S L 1964 A technique for maximizing details in numerical weather map analysis; J. Appl. Meteorol. 3 396-409.

Boyer T P and Levitus S 1994 Quality control and processing of historical temperature, salinity, and oxygen data; NOAA Atlas NESDIS 81.

Boyer T P, Stephens C, Antonov J I, Locarnini R A, O'Brien T D and Garcia H E 2002 World Ocean Atlas 2001, Volume 2: Salinity. NOAA Atlas NESDIS 50, NOAA, U.S. Government Printing Office, Washington D.C.

Bruce J G, Johnson D R and Kindle J C 1994 Evidence for eddy formation in the eastern Arabian Sea during the northeast monsoon; J. Geophys. Res. 99 7651-7664.

Daneshzadeh Y C, Festa J F and Minton S M 1994 Procedures used at AOML to quality control real time XBT data collected in the Atlantic Ocean; NOAA Technical Memorandum ERL AOML-78.

Durand F, Shetye S R, Vialard J, Shankar D, Shenoi S S C, Ethe C and Madec G 2004 Impact of temperature inversions on SST evolution in the southeastern Arabian Sea during the pre-summer monsoon season; Geophys. Res. Lett. 31 1-4.

Durand F, Shankar D, DeBoyer Montegut C, Shenoi S S C, Blanke B and Madec G 2007 Modeling the barrier-layer formation in the southeastern Arabian Sea; J. Climatol. 20 2109-2120.

Durand F, Papa F, Rahman A and Bala S 2011 Impact of Ganges-Brahmaputra interannual discharge variations on Bay of Bengal temperature and salinity variations during the 1992-1999 period; J. Earth Syst. Sci. 120 859-872, doi: 10.1007/s12040-011-0118-x.

Fekete B, Vorosmarty C and Grabs W 2002 High resolution fields of global runoff combining observed river discharge and simulated water balances; Global Biogeochem. Cycles 16, doi: 10.1029/1999GB001254.3.

Fofonoff N P and Milland R C 1983 Algorithms for computation of fundamental properties of seawater; UNESCO technical papers in marine sciences 44, UNESCO.

Gadgil S and Srinivasan J 1990 Low-frequency variation of tropical convergence zones; Meteorol. Atmos. Phys. 44 119-132.

Gopalakrishna V V, Johnson Z, Salgaonkar G, Nisha K and Rajan C K 2005 Observed variability of sea surface salinity and therman inversions in the Lakshadweep Sea during contrast monsoons; Geophys. Res. Lett. 32, doi: 10.1029/2005GL023280.

Gouretski V and Koltermann K P 2007 How much is the ocean really warming?; Geophys. Res. Lett. 34, doi: 10.1029/2006GL027834.

Han W and McCreary J P 2001 Modeling salinity distributions in the Indian Ocean; J. Geophys. Res. 106 859-877. 
Hanawa K, Raul P, Bailey R, Sy A and Szabados M 1994 Calculation of new depth equations for expendable bathythermographs using a temperature-error-free method (application to Sippican/TSK T-7, T-6 and T-4 XBTs); IOC Tech. Series 4244.

Ishii M, Souji A, Sugimoto S and Matsumoto T 2005 Objective analyses of sea-surface temperature and marine meteorological variables for the 20th century using ICOADS and the KOBE collection; Int. J. Climatol. 25 865-879.

Ishii M, Kimoto M, Sakamoto K and Iwasaki S I 2006 Steric sea level changes estimated from historical ocean subsurface temperature and salinity; J. Oceanogr. 62 155-170.

Joseph P V 1990 Warm pool over the Indian Ocean and monsoon onset; Tropical ocean and atmosphere, Newsletter $\mathbf{5 3}$ $1-5$.

Joseph P V, Sooraj K P, Babu C A and Sabin T P 2005 A cold pool in the Bay of Bengal and its interaction with the active-break cycle of the monsoon; CLIVAR Exch. 34 $1010-12$.

Kessler W S and McCreary J P 1993 The annual wind-driven Rossby wave in the subthermocline equatorial Pacific; J. Phys. Oceanogr. 23 1192-1207.

Kurian J and Vinayachandran P N 2007 Mechanisms of formation of the Arabian Sea mini warm pool in a highresolution Ocean General Circulation Model; Geophys. Res. Lett. 112, doi: 10.1029/2006JC003631 (C05009).

Levitus S 1982 Climatological atlas of the world ocean; NOAA Professional Paper 13, NOAA, U.S. Government Printing Press, Washington D.C.

Levitus S and Boyer T P 1994 World Ocean Atlas 1994, Volume 4: Temperature; NOAA Atlas NESDIS 4, 117p.

Levitus S, Burgett R and Boyer T P 1994 World Ocean Atlas 1994, Volume 3: Salinity; NOAA Atlas NESDIS 3, 99p.

Levitus S, Antonov J I, Boyer T P, Locarnini R A, Garcia H E and Mishonov A V 2009 Global ocean heat content 1955-2008 in light of recently revealed instrumentation problems; Geophys. Res. Lett. 36, doi: 10.1029/2008GL037155.

Locarnini R A, Mishonov A V, Antonov J I, Boyer T P and Garcia H E 2006 World Ocean Atlas 2005, Volume 1: Temperature. NOAA Atlas NESDIS 61, NOAA, U.S. Government Printing Office, Washington D.C.

Locarnini R A, Mishonov A V, Antonov J I, Boyer T P and Garcia H E 2010 World Ocean Atlas 2009, Volume 1: Temperature; NOAA Atlas NESDIS 68, NOAA, U.S. Government Printing Office, Washington D.C.

Lozier M S, Owens W B and Curry R G 1995 The climatology of the North Atlantic; Prog. Oceanogr. 36 $1-44$.

Lynn R G and Reid J L 1968 Characteristics and circulation of deep and abyssal waters; Deep-Sea Res. 15 577-598.

McCreary J P, Kundu P K and Molinari R L 1993 A numerical investigation of the dynamics, thermodynamics and mixed-layer processes in the Indian Ocean; Prog. Oceanogr. 31 181-244.

Rabiner L R, Sambur M R and Schmidt C E 1975 Application of a nonlinear smoothing algorithm to speech processing; IEEE Trans. Acoustics Speech Signal Proc. 23 $552-557$.

Rao R R and Sivakumar R 1999 On the possible mechanisms of the evolution of a mini-warm pool during the pre-summer monsoon season and the onset vortex in the southeastern Arabian Sea; Quart. J. Roy. Meteorol. Soc. 125 787-809.

Rao R R, Kumar M S G, Ravichandran M, Samala B K and Anitha G 2006a Observed intra-seasonal variability of mini-cold pool off the southern tip of India and its intrusion into the south central Bay of Bengal during summer monsoon season; Geophys. Res. Lett. 33, doi: 10.1029/2006GL026086.

Rao R R, Kumar M S G, Ravichandran M, Samala B K and Sreedevi N 2006b Observed mini-cold pool off the southern tip of India and its intrusion into the south central Bay of Bengal during summer monsoon season; Geophys. Res. Lett. 33, doi: 10.1029/2005GL025382.

Rattray M 1962 Interpolation errors and oceanographic sampling; Deep-Sea Res. 9 25-37.

Reiniger R F and Ross C F 1968 A method of interpolation with application to oceanographic data; Deep-Sea Res. 9 185-193.

Reynolds R W, Rayner N A, Smith T M, Stokes D C and Wang W 2002 An improved in situ and satellite SST analysis for climate; J. Climate 15 1609-1625.

Rochford D J 1964 Salinity maxima in the upper $1000 \mathrm{~m}$ of the north Indian Ocean; Aust. J. Mar. Freshwater Res. 15 1-24.

Saunders P M and Fofonoff N P 1976 Conversion of pressure to depth in the ocean; Deep-Sea Res. 23 109-111.

Shankar D and Shetye S R 1997 On the dynamics of the Lakshadweep high and low in the southeastern Arabian Sea; J. Geophys. Res. 102 12,551-12,562.

Shankar D, Vinayachandran P N and Unnikrishnan A S 2002 The monsoon currents in the north Indian Ocean; Prog. Oceanogr. 52 63-120.

Shankar D, Kotamraju V and Shetye S R 2004 A quantitative framework for estimating water resources in India; Curr. Sci. 86 543-552.

Shankar D, Shetye S R and Joseph P V 2007 Link between convection and meridional gradient of sea surface temperature in the Bay of Bengal; J. Earth Syst. Sci. 116 385-406.

Shenoi S S C, Shetye S R, Gouveia A D and Michael G S 1993 Salinity extrema in the Arabian Sea; In: Monsoon biogeochemistry (eds) Ittekot $\mathrm{V}$ and Nair $\mathrm{R} \mathrm{R}$, Mitt. Geol.-Paläont. Inst. Univ. Hamburg, SCOPE/UNEP Sonderband, 76 37-49.

Shenoi S S C, Shankar D and Shetye S R 1999 On the sea surface temperature high in the Lakshadweep Sea before the onset of the southwest monsoon; J. Geophys. Res. (C: Oceans) 104 15,703-15,712.

Shenoi S S C, Shankar D and Shetye S R 2002 Differences in heat budgets of the near-surface Arabian Sea and Bay of Bengal: Implications for the summer monsoon; J. Geophys. Res. 107, doi: 10.1029/2000JC000679.

Shetye S R 1993 The movement and implications of the Ganges-Brahmaputra runoff on entering the Bay of Bengal; Curr. Sci. 64 32-38.

Shetye S R, Gouveia A D, Shenoi S S C, Michael G S, Sundar D, Almeida A M and Santanam K 1991 The coastal current off western India during the northeast monsoon; Deep-Sea Res. 38 1517-1529.

Shetye S R, Gouveia A D, Shankar D, Shenoi S S C, Vinayachandran P N, Sundar D, Michael G S and Nampoothiri G 1996 Hydrography and circulation in the western Bay of Bengal during the northeast monsoon; J. Geophys. Res. 101 14,011-14,025.

Shuman F G 1957 Numerical method in weather prediction: II. Smoothing and filtering; Mon. Weather Rev. 85 357-361.

Sikka D R and Gadgil S 1980 On the maximum cloud zone and the ITCZ over India longitude during the southwest monsoon; Mon. Weather Rev. 108 1840-1853.

Stephens C, Antonov J I, Boyer T P, Conkright M E, Locarnini R A, O'Brien T D and Garcia H E 2002 World Ocean Atlas 2001, Volume 1: Temperature; NOAA Atlas NESDIS 49, NOAA, U.S. Government Printing Office, Washington D.C. 
Stommel H M and Fieux M 1978 Oceanographic atlases: A guide to their geographic coverage and contents (USA: Woods Hole Press).

Tukey J W 1974 Nonlinear (nonsuperposable) methods for smoothing data; Cong. Rec. 1974 EASCON, p. 673.

Vinayachandran P N and Shetye S R 1991 The warm pool in the Indian Ocean; Proc. Indian Acad. Sci. (Earth Planet. Sci.) $100165-175$.

Webb D J, Killworth P D, Coward A and Thompson S 1991 The FRAM Atlas of the Southern Ocean; Natural Environment Research Council, Swindon, England.

Wijffels S E, Willis J, Domingues C M, Barker P, White N J, Gronell A, Ridgway K and Church J A 2008
Changing expendable bathythermograph fall rates and their impact on estimates of thermosteric sea level rise; J. Climatol. 21 5657-5672.

Wyrtki K 1971 Oceanographic atlas of the International Indian Ocean Expedition (Washington D.C.: National Science Foundation).

Xie P and Arkin P A 1997 Global precipitation: A 17year monthly analysis based on gauge observations, satellite estimates, and numerical model outputs; Bull. Am. Meteorol. Soc. 78 2539-2558.

Yaremchuk M, Yu Z and McCreary J P 2005 River discharge into the Bay of Bengal in an inverse ocean model; Geophys. Res. Lett. 32, doi: 10.1029/2005GL023750. 